NBER WORKING PAPER SERIES

\title{
DOES INDIVISIBLE LABOR EXPLAIN THE DIFFERENCE BETWEEN MICRO AND MACRO ELASTICITIES? A META-ANALYSIS OF EXTENSIVE MARGIN ELASTICITIES
}

\author{
Raj Chetty \\ Adam Guren \\ Dayanand S. Manoli \\ Andrea Weber \\ Working Paper 16729 \\ http://www.nber.org/papers/w16729 \\ NATIONAL BUREAU OF ECONOMIC RESEARCH \\ 1050 Massachusetts Avenue \\ Cambridge, MA 02138 \\ January 2011
}

We would like to thank Daron Acemoglu, Orazio Attanasio, Mark Bils, Richard Blundell, Gregory Bruich, David Card, John Friedman, Bob Hall, Greg Mankiw, Jonathan Parker, Luigi Pistaferri, Richard Rogerson, Michael Woodford, Robert Shimer, Danny Yagan, Susan Yang, and the conference participants for helpful comments. We are extremely grateful to Peter Ganong and Jessica Laird for outstanding research assistance. Thanks to Richard Rogerson and Johanna Wallenius for sharing their simulation code. Funding was provided by the Lab for Economic Applications and Policy at Harvard University and the National Science Foundation. The views expressed herein are those of the authors and do not necessarily reflect the views of the National Bureau of Economic Research.

NBER working papers are circulated for discussion and comment purposes. They have not been peerreviewed or been subject to the review by the NBER Board of Directors that accompanies official NBER publications.

(C) 2011 by Raj Chetty, Adam Guren, Dayanand S. Manoli, and Andrea Weber. All rights reserved. Short sections of text, not to exceed two paragraphs, may be quoted without explicit permission provided that full credit, including $(\mathbb{C}$ notice, is given to the source. 
Does Indivisible Labor Explain the Difference Between Micro and Macro Elasticities? A Meta-Analysis of Extensive Margin Elasticities

Raj Chetty, Adam Guren, Dayanand S. Manoli, and Andrea Weber

NBER Working Paper No. 16729

January 2011, Revised August 2011, Revised June 2012

JEL No. E24,E32,J22

\begin{abstract}
Macroeconomic calibrations imply much larger labor supply elasticities than microeconometric studies. One prominent explanation for this divergence is that indivisible labor generates extensive margin responses that are not captured in micro studies of hours choices. We evaluate whether existing calibrations of macro models are consistent with micro evidence on extensive margin responses using two approaches. First, we use a standard calibrated macro model to simulate the impacts of tax policy changes on labor supply. Second, we present a meta-analysis of quasi-experimental estimates of extensive margin elasticities. We find that micro estimates are consistent with macro evidence on the steady-state (Hicksian) elasticities relevant for cross-country comparisons. However, micro estimates of extensive-margin elasticities are an order of magnitude smaller than the values needed to explain business cycle fluctuations in aggregate hours. Hence, indivisible labor supply does not explain the large gap between micro and macro estimates of intertemporal substitution (Frisch) elasticities. Our synthesis of the micro evidence points to Hicksian elasticities of 0.3 on the intensive and 0.25 on the extensive margin and Frisch elasticities of 0.5 on the intensive and 0.25 on the extensive margin.
\end{abstract}

Raj Chetty

Department of Economics

Harvard University

1805 Cambridge St.

Cambridge, MA 02138

and NBER

chetty@fas.harvard.edu

Adam Guren

Department of Economics

Harvard University

1805 Cambridge St.

Cambridge, MA 02138

guren@fas.harvard.edu
Dayanand S. Manoli

Department of Economics

University of California, Los Angeles

8283 Bunche Hall

Box 951477

Los Angeles, CA 90095-1477

and NBER

dsmanoli@econ.ucla.edu

Andrea Weber

University of Mannheim

Economics Department

L7, 3-4

68131 Mannheim

Germany

a.weber@uni-mannheim.de

An online appendix is available at:

http://www.nber.org/data-appendix/w16729 


\section{Introduction}

Macroeconomic models of fluctuations in hours of work over the business cycle or across countries imply much larger labor supply elasticities than microeconometric estimates of hours elasticities. Understanding this divergence is critical for questions ranging from the sources of business cycles to the impacts of tax policy on growth and inequality. Starting with the seminal work of Rogerson (1988) and Hansen (1985), one leading explanation of the divergence is the extensive margin response created by indivisible labor supply. If labor supply is indivisible, changes in tax or wage rates can generate large changes in aggregate hours by inducing extensive margin (participation) responses even if they have little effect on hours conditional on employment. In view of this argument, modern macro models are calibrated to match low micro estimates of intensive margin elasticities. However, the extensive margin elasticity is usually treated as a free parameter that can be calibrated purely to match macroeconomic moments.

We argue that the extensive margin elasticity should not be treated as a free parameter. Macro models should be calibrated to match micro estimates of extensive margin elasticities in the same way that they are calibrated to match micro estimates of intensive margin elasticities. The size of the extensive margin responses depends on the density of the distribution of reservation wages around the economy's equilibrium. The same marginal density that determines the impacts of macroeconomic variation on aggregate employment also determines the impacts of quasi-experiments such as tax policy changes on employment rates. Micro estimates of extensive margin elasticities can therefore be used to calibrate macro models. ${ }^{1}$

In this paper, we assess whether existing calibrations of macro models are consistent with micro evidence on extensive margin responses. In doing so, we find that it is crucial to distinguish between two types of elasticities: Hicksian and Frisch. The Frisch (marginal utility constant) elasticity controls intertemporal substitution responses to temporary wage fluctuations and is therefore the relevant parameter for understanding labor supply fluctuations over the business cycle. ${ }^{2}$ The Hicksian (wealth constant) elasticity controls steady-state responses

\footnotetext{
${ }^{1}$ The distribution of reservation wages at the margin could vary across subgroups, potentially generating differences between micro and macro estimates of extensive-margin responses. As we explain below, observable heterogeneity in elasticities across subgroups reinforces our conclusions.

${ }^{2}$ The extensive margin Frisch elasticity is technically ill-defined because each agent is not at an interior optimum. We therefore define the Frisch extensive elasticity empirically as the impact of an infinitismal, tem-
} 
to permanent wage changes and is therefore the relevant parameter for understanding differences in labor supply across countries with different tax systems. We use two approaches to comparing macro calibrations with micro evidence: simulations of quasi-experiments and a meta-analysis of micro elasticity estimates. Both approaches show that micro and macro evidence agree about Hicksian (steady state) elasticities but disagree about Frisch (intertemporal substitution) elasticities.

We begin by simulating the impacts of policy changes that generate exogenous changes in incentives to work in a standard macro model and comparing the predicted responses with the findings of microeconometric studies. We use Rogerson and Wallenius' (2009) [RW] calibrated model of life cycle labor supply as a benchmark model for this exercise. The RW model matches macro evidence by generating an intertemporal substitution elasticity of aggregate hours above 2 even when calibrated to generate a Frisch intensive-margin elasticity below 0.5. We simulate labor supply responses to three policies using this model: (1) a tax-free year in Iceland in 1987 studied by Bianchi et al. (2001), (2) a randomized experiment providing temporary subsidies for work to welfare recipients in Canada (Card and Hyslop 2005), and (3) the 1994 expansion of the Earned Income Tax Credit (EITC) for low-income individuals in the United States (Meyer and Rosenbaum 2001). The first two examples are ideal for identifying Frisch elasticities because they induce temporary variation in wage rates. Bianchi et al. (2001) find that employment rates in Iceland do indeed rise in 1987, but the increase is only one fifth as large as that predicted by the RW model. Similarly, the calibrated RW model predicts intertemporal substitution responses to the work subsidies in Canada that are nearly four times larger than what Card and Hyslop observe in their data. The third example - the EITC expansion - generates permanent variation in tax rates and thus is well-suited for identifying steady-state elasticities. The RW model performs better in matching the impacts of the EITC expansion on employment rates because it generates a Hicksian aggregate hours elasticity of approximately 0.7 , resulting in steady-state impacts of taxes on labor supply that are closer to micro estimates.

While our quantitative results rest on the particular assumptions of the RW model, our qualitative conclusions apply more generally. Any macro model that relies primarily on changes porary wage change on employment rates. This is the relevant elasticity for evaluating employment responses to business cycle fluctuations. 
in labor supply to generate business cycle fluctuations must feature a large extensive margin Frisch elasticity. As a result, any such model will over-predict the response to temporary wage changes such as the tax holiday in Iceland and work subsidies in Canada. Intuitively, fluctuations in employment over the business cycle and the employment effects of quasi-experimental wage changes are both fundamentally determined by the same density of the reservation wage distribution at the margin irrespective of model specification. Thus, any labor supply model that fits the quasi-experimental evidence cannot generate large fluctuations in employment over the business cycle.

To explore whether the results of the three studies we consider in the simulations are representative of the broader empirical literature, we conduct a meta-analysis of quasi-experimental estimates of extensive margin elasticities. We summarize results from fifteen studies that span a broad range of countries, demographic groups, time periods, and sources of variation. These studies generally analyze changes in incentives for small subgroups of the population, permitting identification of labor supply elasticities that are not confounded by changes in equilibrium wage rates. Despite the great variation in methodologies, there is consensus about extensive margin elasticities. The mean extensive margin elasticity among the studies we consider is 0.28 and every estimate is below 0.43. The intertemporal substitution (Frisch) elasticity estimates for temporary policy changes turn out be quite similar to the steady-state elasticity estimates obtained from permanent policy changes. The small elasticities imply that most individuals are at a corner in their employment choices; that is, the density of individuals at the margin of employment is thin in practice.

We conclude our analysis by evaluating whether extensive margin elasticities of around 0.25 as suggested by micro evidence are adequate to reconcile the gap between micro and macro estimates of aggregate hours elasticities. To do so, we summarize micro and macro estimates of Hicksian and Frisch elasticities on both the extensive and intensive margins. We find that micro and macro studies agree about the steady-state impacts of taxes on labor supply. Both micro and macro studies imply Hicksian extensive margin elasticities around 0.2. And both micro and macro evidence are consistent with intensive margin elasticities around 0.3 once one accounts for frictions that may attenuate observed micro estimates (Chetty et al. 2011a, Chetty 2012). Prescott's (2004) widely-cited cross-country dataset implies an aggregate hours 
(extensive plus intensive) Hicksian elasticity of 0.7 , only slightly larger than micro estimates. ${ }^{3}$ These findings indicate that labor supply responses to taxation could indeed explain much of the variation in hours of work across countries with different tax systems. ${ }^{4}$

On the intertemporal substitution margin, the limited existing evidence on intensive margin elasticities suggests that values around 0.5 are consistent with both micro and macro data. However, micro and macro estimates of extensive margin intertemporal substitution elasticities differ by an order of magnitude. Quasi-experimental estimates of extensive margin intertemporal substitution elasticities are around 0.25. In contrast, pure equilibrium macro models, in which employment fluctuations are driven purely by preferences, imply intertemporal substitution extensive margin elasticities in excess of 2. Hence, the puzzle to be resolved is why employment rates fluctuate so much over the business cycle relative to what one would predict based on the impacts of tax changes on employment rates - that is, why micro and macro estimates of the Frisch extensive margin elasticity are so different. ${ }^{5}$ Even accounting for indivisible labor, micro studies do not support representative-agent macro models that generate Frisch elasticities above 1.

There are two potential concerns that one may have with using microeconomic estimates to calibrate macroeconomic models. The first is that heterogeneity in extensive margin responses complicates the mapping from micro estimates to macro elasticities that reflect economy-wide behavior. ${ }^{6}$ This problem is compounded by the concern that micro studies sometimes exclude important subgroups that could matter for economy-wide extensive margin responses (Dyrda et al. 2012). In practice, however, heterogeneity across subgroups appears to strengthens our main conclusion about agreement on the Hicksian elasticity but disagreement on the Frisch

\footnotetext{
${ }^{3}$ Prescott reports an elasticity of approximately 3 in his paper. Importantly, this is a Frisch rather than Hicksian elasticity. Prescott implicitly maps the Hicksian elasticity of 0.7 implied by the data to a Frisch elasticity of 3 based on specific parametric assumptions. See Section 2 below for further details.

${ }^{4}$ Other factors, such as institutions or regulations, could also play a significant role in explaining cross-country hours differences (Alesina, Glaeser, and Sacerdote 2005). Our analysis does not rule out the importance of such factors. We simply show that micro estimates of labor supply elasticities are consistent with observed differences in aggregate hours across countries with different tax systems.

${ }^{5}$ Some progress has been made in recent years on this front: for instance, search and matching models with rigid wages (e.g. Hall 2009) can potentially match business cycle fluctuations with smaller extensive margin labor supply elasticities.

${ }^{6}$ Note that the same problem could in principle arise with intensive margin elasticities as well. Although macro models are often parametrized so that the intensive margin elasticity is constant by assumption, there is no economic reason for intensive margin elasticities to remain constant as wage rates change. Hence, if one is willing to use micro estimates to calibrate intensive margin elasticities, one should be equally willing to do so on the extensive margin as well.
} 
elasticity. The heterogeneity in micro estimates of extensive-margin Hicksian elasticities mirrors the heterogeneity observed in macro studies of steady-state responses. For instance, both micro and macro studies indicate that extensive-margin elasticities are higher for subgroups that are less attached to the labor force, such as single mothers and individuals near retirement. However, heterogeneity magnifies the discrepancy between micro and macro estimates of intertemporal substitution elasticities. Most notably, employment rates fluctuate substantially over the business cycle even for prime-age males, which stands in sharp contrast with the near-zero micro extensive margin Frisch elasticity estimates for this group.

A second potential concern in mapping micro estimates to macro labor supply elasticities is that reduced-form micro studies may not directly identify the structural primitives of the reservation wage distribution that control extensive margin labor supply choices. This is particularly a concern if frictions prevent the labor market from clearing, as our analysis suggests. In a model with frictions, reduced-form micro elasticity estimates represent a convolution of the density of the reservation wage distribution at the margin and other structural parameters, such as the distribution of adjustment costs or search frictions or the degree of liquidity constraints. Importantly, the same reduced-form elasticities would also determine the impact of wage changes on labor supply over the business cycle in such an environment. Hence, micro estimates should continue to provide useful targets for calibrating macro models even though they do not identify the structure of preferences or other primitives necessary for normative analysis. ${ }^{7}$ However, especially when reduced-form elasticities combine several structural parameters, they may not be stable across settings. Because of this instability, one should not seek to calibrate macro models to match any single estimate of a micro elasticity. Nevertheless, one can gauge the range of plausible magnitudes by pooling evidence from many different studies and settings as we do here. The fact that every quasi-experimental study we review finds elasticities significantly less than 0.5 casts doubt upon macro models calibrated with extensive margin elasticities above 1.

The paper is organized as follows. The next section briefly reviews the existing literature on indivisible labor. In Section 3, we establish a terminology for the various elasticity

\footnotetext{
${ }^{7}$ Some micro studies attempt to strip out frictions by studying subgroups such as bike messengers or taxi drivers who can choose their daily labor supply more freely. However, it is not clear that these pure labor supply elasticity estimates are more relevant for macro calibrations. If the same frictions that constrain salaried workers from responding to tax changes also contrain their responses to fluctuations over the business cycle, then it is the observed reduced-form elasticity for the average worker that matters.
} 
concepts, as these terms are often used in different ways in the existing literature. Section 4 reports simulations of the three quasi-experiments in the Rogerson and Wallenius (2009) model. Section 5 presents the meta-analysis of micro estimates. In Section 6, we compare micro and macro evidence on the intensive and extensive margins. Section 7 concludes. Details of the simulation methods and meta-analysis are given in the appendix.

\section{Indivisible Labor: Background}

Equilibrium macroeconomic models - in which differences in hours of work are driven by preferences - require large labor supply elasticities to explain the variation in hours of work over the business cycle and across countries with different tax regimes. In contrast, quasiexperimental microeconometric studies of the impacts of tax reforms on hours of work and earnings typically obtain elasticities close to zero for most groups except very high income earners. $^{8}$

A large literature has posited that the discrepancy between micro and macro elasticities can be explained by indivisibilities in labor (e.g. Hansen 1985, Rogerson 1988, Cho and Rogerson 1988, Christiano and Eichenbaum 1992, Cho and Cooley 1994, King and Rebelo 1999, Chang and Kim 2006, Ljungqvist and Sargent 2006, Prescott, Rogerson, and Wallenius 2009, Rogerson and Wallenius 2009). ${ }^{9}$ If individuals cannot freely choose hours of work or face fixed costs of entry, aggregate employment depends upon the distribution of reservation wages in the economy. If this distribution has substantial density at the margin - i.e., many individuals are indifferent between working and not working at prevailing wage rates - then a small reduction in wage rates could reduce aggregate hours of work significantly because many individuals will stop working. Yet the same change in wage rates may not affect hours of work conditional on employment very much, implying a small intensive margin labor supply elasticity. As a result, a model with large extensive margin elasticities and small intensive margin elasticities could match both the micro and macro evidence. Motivated by these results, modern macro

\footnotetext{
${ }^{8}$ Early estimates of intensive-margin elasticities include MaCurdy (1981), Altonji (1986), and Angrist (1991). Blundell and MaCurdy (1999) review this literature. Chetty (2009) and Saez, Slemrod, and Giertz (2011) summarize more recent quasi-experimental intensive margin elasticity estimates.

${ }^{9}$ The literature has taken two approaches to aggregation with indivisible labor supply: aggregation over states via employment lotteries (e.g. Hansen 1985, Rogerson 1988) or aggregation over time periods in a lifecycle model (e.g. Mulligan 2001, Ljungqvist and Sargent 2006, Prescott, Rogerson, and Wallenius 2009). The micro evidence on extensive margin responses we review here is most easily interpreted through the modern life cycle models.
} 
models are calibrated to match micro estimates of intensive margin elasticities but typically calibrate the extensive margin elasticity purely to match macroeconomic moments (King and Rebelo 1999, Rogerson and Wallenius 2009, Ljungqvist and Sargent 2011).

In parallel with the development of macro models of indivisible labor supply, a large microeconometric literature has recognized the importance of the extensive margin in the analysis of labor supply. Ashenfelter (1984) and Heckman (1984) discuss the importance of extensive margin labor supply choices in the analysis of aggregate fluctuations. Heckman and Killingsworth (1986) and Heckman (1993) review the literature on labor supply models that explicitly model participation decisions. More recent research has estimated extensive margin elasticities using quasi-experimental methods.

However, macro models have not been calibrated to match micro evidence on extensive margin elasticities. One complication in performing such a calibration is that extensive margin elasticities vary with the wage rate unless the density of the reservation wage distribution happens to be uniform. Hence, any micro estimate of an extensive margin elasticity is necessarily local to the wage variation used for identification. However, this argument does not justify treating the extensive margin elasticity as a free parameter for two reasons. First, if the micro estimates are identified using variation similar to that used in macroeconomic comparisons, one will obtain the appropriate local elasticity relevant for macro calibrations. Second, the same problem arises when calibrating macro models with micro estimates of intensive margin elasticities, insofar as elasticities will only be constant on the intensive margin if utility happens to produce a constant-elasticity labor supply function. We revisit this issue in Section 6 and show that, if anything, observable heterogeneity in elasticities reinforces the conclusions drawn below.

\section{Terminology}

It is helpful to establish some conventions about terminology given the various elasticity concepts discussed in this paper. We distinguish between elasticities based on the margin of response (extensive vs. intensive) and the timing of response (intertemporal substitution vs. steady state). There are four elasticities of interest: steady-state extensive, steady-state intensive, intertemporal extensive, and intertemporal intensive. Each of these four elasticities 
can be estimated using both micro (quasi-experimental) and macroeconomic variation. We use the terms "micro" and "macro" elasticities exclusively to refer to the source of variation used to estimate the elasticity. The elasticity of aggregate hours - the relevant parameter for calibrating a representative agent model - is the sum of the extensive and intensive margin elasticities, weighted by hours of work if individuals have heterogeneous preferences (Blundell, Bozio, and Laroque 2011).

The macro literature uses the term "macro elasticity" to refer to the Frisch elasticity of aggregate hours and "micro elasticity" to refer to the intensive-margin elasticity of hours conditional on employment (e.g. Prescott 2004, Rogerson and Wallenius 2009). We use different terminology here for two reasons. First, the intensive-margin is no more "micro" than the extensive margin; both are determined by household-level choices and both have been estimated using micro data. Second, and more importantly, the Frisch elasticity is critical for understanding business cycle fluctuations in models where aggregate hours fluctuations are purely driven by labor supply, but it is not the relevant parameter for evaluating the steady-state impacts of differences in taxes across countries. The Frisch (marginal utility constant) elasticity controls intertemporal substitution responses to temporary wage fluctuations, while the Hicksian (wealth constant) elasticity controls steady-state responses and the welfare consequences of taxation (MaCurdy 1981, Auerbach 1985). ${ }^{10}$

The distinction between Hicksian and Frisch elasticities is quite important in practice. Prescott (2004) reports that cross-country differences in aggregate hours imply an elasticity of 3 in a representative-agent model, whereas Davis and Henrekson (2005) estimate an elasticity of 0.33 using similar data. The difference arises primarily because Prescott reports a Frisch elasticity whereas Davis and Henrekson report a Hicksian elasticity. Regressing log hours on log tax rates in Prescott's data yields a Hicksian elasticity of 0.7, as shown in Figure 2a below. Prescott maps this estimate of the Hicksian elasticity into a value for a Frisch elasticity based on parametric assumptions about utility and the wealth-earnings ratio. When utility is time-separable, the Frisch $\left(\varepsilon^{F}\right)$ and Hicksian $\left(\varepsilon^{H}\right)$ elasticities are related by the following

\footnotetext{
${ }^{10}$ The Hicksian elasticity determines the impact of taxes in steady-state if government revenues are returned to the consumer as a lump sum, as commonly assumed in representative-agent macro models. If revenues are not returned to consumers, tax changes have income effects and the Marshallian elasticity becomes the relevant parameter.
} 
identity (Ziliak and Kniesner 1999, Browning 2005):

$$
\varepsilon^{F}=\varepsilon^{H}+\rho\left(\frac{d[w l]}{d A}\right)^{2} \frac{A}{w l},
$$

where $\rho$ is the elasticity of intertemporal substitution (EIS), $\frac{d[w l]}{d A}$ is the marginal propensity to earn out of unearned income, and $\frac{A}{w l}$ is the ratio of assets to earnings. The reason that Prescott obtains a much larger value of $\varepsilon^{F}$ than $\varepsilon^{H}$ is that the parametric utility specification he uses produces large values of $\frac{A}{w l}$ and $\frac{d[w l]}{d A}$. However, microeconometric evidence shows that income effects on labor supply are much smaller than those produced by the Prescott utility specification (Holtz-Eakin, Joulfaian, and Rosen 1993, Imbens et al. 2001). Under a utility specification that matches empirical estimates of the mean values of $\frac{d[w l]}{d A}$ and $\frac{A}{w l}$, the Frisch elasticity is only slightly larger than the Hicksian elasticity because the difference between the two elasticities is proportional to the income effect squared $\left(\frac{d[w l]}{d A}\right)^{2}$ (Chetty 2012, Table III). ${ }^{11}$

\section{Simulations of Quasi-Experiments in the RW Model}

We evaluate whether macro models with indivisible labor are consistent with micro evidence on extensive margin responses by focusing on the Rogerson and Wallenius (2009) model. The RW model is a leading example of recent models of indivisible labor that aggregate over individuals by time-averaging over the life cycle, as in Ljungqvist and Sargent (2006). The model is wellsuited for our purposes because it features both an extensive and intensive margin of labor supply. RW calibrate their model to show that small intensive-margin micro elasticities are consistent with a large Frisch elasticity of aggregate hours. We adopt the parameters chosen by RW and simulate the impacts of policy changes analyzed in three prominent microeconometric studies. $^{12}$

Setup. RW analyze an overlapping-generations model in which a unit mass of agents is born at each instant and lives for one unit of time. An individual who supplies $h(a) \in[0,1]$ hours at age $a$ produces $e(a) \times \max \{h(a)-\bar{h}, 0\}$ efficiency units of labor, where $e(a)=$

\footnotetext{
${ }^{11}$ Subsequent studies calibrate models to match Prescott's Frisch elasticity of 3, but choose a different functional form for utility and wealth-earnings ratios (e.g. Trabandt and Uhlig 2009). The conclusions drawn by these studies - e.g. that reductions in tax rates would increase tax revenue - might differ had they directly matched the steady state elasticity of 0.7 implied by Prescott's data.

${ }^{12}$ On the intertemporal substitution margin, we sought to maximize the model's chance of fitting the data by analyzing the two studies that obtain the largest intertemporal elasticity estimates among those considered in our meta analysis (Table 1). On the steady-state response, we chose a representative study of a well-known policy (the Earned Income Tax Credit) to show that the model is consistent with typical micro estimates.
} 
$1-2\left(1-e_{1}\right)\left|\frac{1}{2}-a\right|$ is a tent-shaped life-cycle productivity profile and $\bar{h}>0$. Complete asset markets lead to perfect consumption smoothing. With log utility over consumption, each generation solves

$$
\max _{c, h(a)} \log (c)-\alpha \int_{0}^{1} \frac{h(a)^{1+\gamma}}{1+\gamma} d a \text { s.t. } c=(1-\tau) \int_{0}^{1} e(a) \max (h(a)-\bar{h}, 0) d a+T
$$

where $\tau$ is the tax rate and $T$ is a lump-sum tax rebate that balances the government's budget. The model can be solved analytically as described in RW and in the technical appendix. Because wages are paid per efficiency unit, individuals have low hourly wage rates at the beginning and end of their lives and find it optimal not to work at those points. This generates an extensive margin of participation over the life cycle. The convex disutility over hours of work generates an intensive margin hours response to changes in wage rates as well. RW normalize the price of output to 1 and assume a constant-returns-to-scale production technology, so changes in tax rates have no impact on pre-tax wages and prices. Accordingly, the quasi-experiments we simulate also hold pre-tax wages and prices constant, as the studies on which they are based typically analyze the impacts of differential changes in incentives for relatively small subgroups of the population.

RW calibrate the parameters $\alpha, e_{1}$, and $\bar{h}$ to match empirically observed values for the fraction of life worked $(f)$, the maximum hours worked per week over the life cycle $\left(h_{\max }\right)$, and the wage rate at retirement relative to the maximum wage rate over the life cycle $\left(w_{R} / w_{\max }\right)$. Following RW, we set $h_{\max }=45 \%$ (45 hours per week) and $w_{R} / w_{\max }=1 / 2$. We set $f$ to match the aggregate employment rate in the period prior to each policy experiment we consider. The parameter $\gamma$ controls the Frisch elasticity of labor supply, as in standard life cycle models (Card 1990). We set $\gamma=2$ to obtain an intensive margin Frisch elasticity of $\varepsilon_{\mathrm{INT}}=\frac{1}{\gamma}=0.5$, consistent with the microeconometric evidence summarized below; we show in Appendix A that setting $\varepsilon_{\text {INT }}=0.25$ yields similar results. ${ }^{13}$ For each of the three tax policy changes simulated below, we choose the model's remaining parameters $\left\{\alpha, e_{1}, \bar{h}\right\}$ to match the moments $\left\{h_{\max }, w_{R} / w_{\max }, f\right\}$ under the tax system prior to the tax change. ${ }^{14}$ In all three

\footnotetext{
${ }^{13} \mathrm{RW}$ show that the intertemporal elasticity of aggregate hours in their model is not sensitive to the intensivemargin intertemporal elasticity. They therefore calibrate $\alpha, e_{1}$, and $\bar{h}$ to match the three moments conditional on various values of $\gamma$.

${ }^{14}$ In one of the simulations, the welfare demonstration in Canada, a small enough fraction of the population is employed prior to the intervention that fitting $w_{R} / w_{\max }=1 / 2$ would require negative productivity at certain points in the life cycle. Consequently, for that simulation, we set $e_{1}=0$, generating $\frac{w_{R}}{w_{\max }}=.615$.
} 
cases, the calibrated model generates an intertemporal substitution elasticity for aggregate hours above 2 despite having an intensive margin intertemporal substitution elasticity of only 0.5 , consistent with RW's main result. ${ }^{15}$ As in RW, we assume that each agent lives for 60 years (corresponding to average adult working lives) and simulate each quasi-experiment by changing the tax rate for the number of periods in the model that correspond to the duration of the tax policy change in the data. ${ }^{16}$

To simulate the impacts of unanticipated tax changes, we must specify how the lump sum rebate $T$ changes for each agent. To simplify aggregation, we assume that each generation receives a lump-sum rebate equal to the taxes they pay at each instant in time. ${ }^{17}$ We ignore heterogeneity in the tax system across individuals and set $\tau$ equal to the average tax rate for the subgroup analyzed (which is relevant for extensive margin decisions).

Experiment 1: Tax Holiday in Iceland. In 1987, Iceland suspended its income tax for one year as it transitioned from a system under which taxes were paid on the previous year's income to a system where taxes were paid on current earnings. In 1987, individuals paid tax on income earned in 1986; in 1988, individuals were taxed on income earned in 1988, and thus income in 1987 was untaxed. The average tax rate was 14.5\% in 1986, 0 in 1987, and 8.0\% in 1988 (Bianchi et al. 2001). Although this tax change could also produce a change in labor demand due to a general equilibrium impact on wage rates, the tax holiday had no impact on labor supply for individuals with low initial tax rates (Bianchi et al. 2001, Figure 9). This implies that the general equilibrium feedback on wage rates was negligible, so the aggregate employment response can be interpreted as a labor supply elasticity. ${ }^{18}$ We simulate the tax reform in Iceland in the RW model under the assumption that the tax system remains stable prior to 1986 and after 1988. The reform was announced in late 1986, so we model the tax change as an unanticipated change at the start of 1987. The average employment rate in the

\footnotetext{
${ }^{15}$ We calculate this and all other Frisch elasticities by simulating the impact of a small, temporary tax change in the RW model. This direct calculation of the Frisch elasticity differs from the values reported by RW. RW report aggregate hours Frisch elasticities for a stand-in household whose behavior matches the aggregate steady-state properties of their economy. However, this stand-in household's behavior does not necessarily match the aggregate intertemporal substitution properties of the RW model.

${ }^{16}$ To characterize high frequency dynamics precisely, we simulate the model with at least 100 periods per year in all cases; see the technical appendix for details.

${ }^{17}$ Tax policy changes affect each generation differently because they are at different points in the lifecycle when the change occurs.

${ }^{18}$ Stated differently, the differential response for workers who experienced larger changes in tax rates can be interpreted as a pure labor supply elasticity that nets out changes in wage rates. Bianchi et al.'s analysis reveals that this differential impact is similar to the aggregate impact we simulate here.
} 
three year period prior to the reform is $f=79.2 \%$, which implies that individuals work for 47.5 years in the model. The single-year tax reduction thus comes close to the ideal experiment for identifying a Frisch elasticity of reducing tax rates for an infinitesimal fraction of the working life.

Figure 1a plots annual changes in employment rates (the employment rate in year $t$ minus the employment rate in year $t-1$ ) around the reform, demarcated by the vertical line. The Icelandic administrative records analyzed by Bianchi et al. (blue squares) show a modest but significant increase in employment rates in 1987 followed by a sharp dip in 1988, consistent with intertemporal substitution. The impact predicted by the RW model (red circles) is an order of magnitude larger than the observed impact. In the data, employment is 3 percentage points higher in 1987 relative to 1988, but the RW model predicts that it would be 13.5 percentage points higher. The model generates a much larger spike in employment because the fraction of cohorts that are close to being indifferent between working and staying out of the labor force is large. The temporary increase in the wage rates therefore induces a large group of agents to work. Note that it is precisely this mechanism - having a large fraction of individual near the margin - that allows the RW model to generate a large Frisch elasticity for aggregate hours and thus explain fluctuations in aggregate hours over the business cycle.

Experiment 2: SSP Welfare Demonstration in Canada. The Iceland analysis focuses on employment changes in the aggregate economy, which are relevant for understanding business cycle fluctuations but may mask substantial heterogeneity across groups. Ljungqvist and Sargent (2006), Rogerson and Wallenius (2007), and others emphasize that certain groups of the population - such an individuals near retirement or those with low wage rates - are likely to exhibit particularly large extensive margin responses and drive the change in aggregate hours. To evaluate whether the model's predictions are more accurate for these more elastic subgroups, we consider a policy experiment targeted at welfare recipients who frequently transition in and out of the labor force.

In the early 1990s, the Canadian government conducted the Self Sufficiency Project (SSP) to test whether a temporary earnings subsidy could induce welfare recipients to start working. The project was a randomized experiment involving over 5,000 single parents who had been on welfare for at least one year. Half the individuals (the treatment group) were given a large 
subsidy if they worked more than 30 hours per week. The subsidy lasted for 36 months. ${ }^{19}$ Under the prevailing welfare system in Canada, welfare payments were reduced dollar-fordollar with earnings above a low baseline level. As a result, a single parent with one child in the control group faced an effective average tax rate of $74.3 \%$ when moving from no work to full-time work (see Appendix A). In contrast, an individual in the treatment group faced an effective average tax rate of $16.7 \%$ for the same change. The employment rate during the month the experiment began was $f=23.5 \%$.

Card and Hyslop (2005) use survey data to calculate employment rates at a monthly frequency for 53 months starting from the month of random assignment. Figure 1b plots monthly employment rates after the experimental intervention began. The series in blue squares shows the difference in employment rates for the treatment group relative to the control group (Card and Hyslop, Figure 3a), with the model the SSP experiment as a tax reform that lowers the tax rate from $\tau=74.3 \%$ to $\tau=16.7 \%$ for a three year period, after which the tax rate reverts to $\tau=74.3 \%$. The pre-experiment employment rate of $23.5 \%$ is added to the difference to facilitate interpretation of the scale. The data show that the subsidy had a substantial impact: employment rates rise by approximately 14 percentage points in the treatment group relative to the control group a year after the subsidy was introduced. These employment gains fade away after the subsidy expires, consistent with intertemporal substitution.

The series in red circles in Figure 1b shows the corresponding impacts predicted by the RW model. Because the sample analyzed by Card and Hyslop consists primarily of younger individuals (less than $2.5 \%$ of the sample is over age 50), we report simulated employment rates for individuals in the first half of the life cycle (ages 16-46). The impacts predicted by the calibrated model - an employment increase of 52.8 percentage points one year after the subsidy is introduced - are again substantially larger than what is observed in the data. Hence, even for subgroups that are closer to the margin of entering or exiting the labor force and are therefore more elastic, the RW model significantly over-predicts extensive margin responses.

One may be concerned that liquidity constraints attenuate the degree of intertemporal

\footnotetext{
${ }^{19}$ Individuals were given up to one year to start working and the 36 month period began after they started to work. This feature of the program generated an incentive to establish eligibility for the subsidy by working within the first year, accentuating the intertemporal substitution incentive. We ignore this feature of the program in our simulation by assuming that the subsidy starts immediately after random assignment. This simplification biases the size of the employment increase predicted by our simulation downward.
} 
substitution in the low-income population treated by the SSP. The estimated elasticity therefore may not directly identify preference parameters in the RW model. However, as noted above, the same liquidity constraints should also affect employment responses to business cycle fluctuations in wage rates. Hence, the reduced-form response estimated by Card and Hyslop is still informative about the magnitude of labor supply fluctuations over the cycle for this subgroup.

Experiment 3: Earned Income Tax Credit in the U.S. The last policy change we consider - the expansion of the EITC in 1994 analyzed by Meyer and Rosenbaum (2000, 2001) and Meyer (2010) - is a permanent tax change whose impact is determined by the Hicksian rather than the Frisch elasticity. ${ }^{20}$ The EITC expansion lowered average tax rates (including implicit taxes generated by the phase-out of transfers) from 50.8\% in 1992 to $43.6 \%$ in 1996 for single mothers (Meyer and Rosenbaum 2000, Table 2). ${ }^{21}$ Roughly half of the expansion occurred in 1994. For simplicity, we model the tax change under the assumption that the change occurs immediately at the start of 1994, ignoring the phase-in of the reform. We also assume as above that the tax system remains stable prior to 1994. The average employment rate for the single mothers is $f=79.1 \%$ in the three years preceding the reform.

Figure 1c shows the employment rates of single mothers around the 1994 reform using data from Meyer (2010, Figure 2). The series in blue circles shows employment rates for single mothers with 1 or 2 children, adjusted for time trends and changes in observables as in Meyer (2010) (see Appendix A for details). The labor force participation rate of single mothers rose from $79.6 \%$ in 1993 to $85.8 \%$ in 1997 after the EITC expansion was fully phased in. The RW model predicts a 6.0 percentage point increase in employment rates on impact and an additional 0.3 percentage point rise over the subsequent 5 years. The impact predicted by the model is thus very similar to the observed impact.

The RW model performs much better in predicting the impacts of the EITC expansion than the preceding experiments because it predicts much smaller steady-state responses than intertemporal substitution responses. Intuitively, a permanent change generates a much

\footnotetext{
${ }^{20}$ If the tax change is not rebated to the consumer as a lump sum, its impact depends on the uncompensated (Marshallian) elasticity rather than the Hicksian elasticity. In practice, microeconometric estimates of income effects are quite small (Holtz-Eakin, Joulfaian, and Rosen 1993, Imbens, Rubin, and Sacerdote 2001), suggesting that the impact of the EITC change is well approximated by the Hicksian elasticity.

${ }^{21}$ The changes in average tax rates in Meyer and Rosenbaum (2000) take into account conurrent changes in benefits from welfare and Medicaid. See Appendix A for details.
} 
lower elasticity because all generations increase their labor supply at the point in their life cycle when they are most productive, smoothing the aggregate response across time. With a temporary change, every generation has an incentive to work when net-of-tax wage rates are high, resulting in a large Frisch elasticity. ${ }^{22}$ In the RW model, a large mass of cohorts is at the margin with respect to a temporary tax change or wage fluctuation because individuals do not have strong preferences over when they work during their lives. However, in any given period, a much smaller fraction of individuals within each cohort are at the margin with respect to a permanent change in incentives.

Together, the simulations highlight two results that we develop further below. First, the extensive margin elasticities required to explain the sharp fluctuations in aggregate hours over the business cycle are far larger than micro estimates. Second, micro and macro evidence are in much closer alignment about the steady-state impacts of taxes on labor supply.

Although the quantitative results of our simulations depend to some extent upon the parametric choices made by RW, we expect these lessons to apply more broadly. Generating a large macro Frisch elasticity by having a large fraction of individuals who are nearly indifferent between working and not working is precisely what delivers predictions about how temporary tax changes affect employment rates that contradict the data. A macro model calibrated to match micro estimates of extensive margin intertemporal substitution elasticities would no longer generate large Frisch elasticities for aggregate hours.

\section{Meta-Analysis}

In this section, we evaluate whether the three quasi-experiments considered above are representative of the broader literature by conducting a meta-analysis of extensive margin elasticity estimates. Although several papers have reviewed intensive margin elasticities (e.g. Pencavel 1986, Blundell and MaCurdy 1999, Chetty 2012), we are not aware of a meta-analysis of quasi-experimental estimates of extensive margin elasticities.

We focus on reduced-form studies that use changes in tax policies or long-term wage trends for identification rather than structural studies that exploit variation in wage rates at the in-

\footnotetext{
${ }^{22}$ Although the SSP welfare demonstration was temporary, a three-year subsidy actually covers a sizable fraction of the working life. The responses to the experiment are therefore determined by a combination of Hicksian and Frisch elasticities. Together, the Iceland and SSP simulations demonstrate that the RW model over-predicts responses both at very short and medium-term frequencies.
} 
dividual level to fully identify a structural model. Keane and Rogerson (2010) argue that obtaining consistent structural estimates from wage variation over the life cycle requires accounting for a broad range of factors such as human capital accumulation (Imai and Keane 2004), credit constraints (Domeij and Floden 2006), and uninsurable risks (Low 2005). Moreover, structural models typically rely on strong exclusion restrictions for identification. ${ }^{23}$ The quasi-experimental studies we consider here exploit variation that is orthogonal to wage rates and thus are more robust to the biases emphasized by Keane and Rogerson. The exclusion restriction underlying these studies is that the differential changes in tax rates across groups is not correlated with unobserved determinants of employment rates, typically a weaker assumption than those required for full identification of a structural model. ${ }^{24}$

Table 1 summarizes extensive margin elasticity estimates from fifteen quasi-experimental studies. The calculations underlying the estimates and standard errors are described in Appendix B. We calculate the extensive margin labor supply elasticity as the change in log employment rates divided by the change in log net-of-tax wage rates. Employment rates are typically defined as working at any point during the year, though there are some differences across studies as described in the appendix. We use the authors' preferred estimate whenever possible. For studies that do not report such an estimate, we construct elasticities from reported estimates of changes in participation and calculations of the change in net-of-averagetax wage rates. We use the delta method to calculate standard errors in such cases.

The studies summarized in Table 1 report labor supply elasticities for various countries and subgroups using many different sources of variation. Yet the elasticity estimates exhibit substantial consensus. The elasticity estimates range from 0.13 to 0.43 , with an overall unweighted mean across the fifteen studies of 0.28. To obtain further insight into the key patterns, we divide the studies into two groups - steady-state and intertemporal substitution - based on the type of variation they use for identification.

\footnotetext{
${ }^{23}$ Common instruments for wage rates include nonlinear age and time trends (Kimmel and Kniesner 1998) or interactions of education and experience (Gourio and Noual 2009) conditional on individual fixed effects. Keane (2010) uses years of schooling as an instrument for the wage to identify an elasticity in Eckstein and Wolpin's (1989) classic structural model. The exclusion restrictions for these instruments are that employment rates do not vary with age conditional on wage rates or that individuals with different levels of education do not have different employment trajectories over their lifecycle. If factors that predict high wage rates also predict high latent tastes for work, the elasticity estimates would be biased upward.

${ }^{24}$ Keane (2010) and Keane and Rogerson (2010) review structural estimates and find larger values than the quasi-experimental estimates summarized below. It would be useful to simulate the impacts of tax policy changes in these structural models to understand why their predictions differ from the reduced-form evidence.
} 
The first panel in Table 1 shows steady-state (Hicksian) elasticities identified from permanent wage changes resulting from tax reforms or long term trends in wage rates across regions or skill-groups. ${ }^{25}$ The simplest empirical designs (e.g. Eissa and Liebman 1996) use difference-in-differences approaches, while more recent studies (e.g. Meghir and Philips 2010) combine multiple reforms over time that affect individuals differently. The mean elasticity across the nine studies that estimate steady-state elasticities is 0.25 .

The second panel in Table 1 summarizes results from studies that exploit temporary wage changes to identify intertemporal substitution (Frisch) elasticities. Some of these studies exploit temporary tax changes such as the Iceland tax holiday discussed above or temporary increases in labor demand, such as Carrington's (1996) analysis of the effect of the Trans-Alaska Pipeline on Alaska's labor market. Other studies analyze the impact of anticipated variation in wages generated by pension schemes on retirement behavior. For instance, Gruber and Wise (1999) correlate employment rates of adults near retirement with the implicit tax generated by social security systems across OECD countries. Their analysis implies an elasticity of 0.23. Brown (2009) and Manoli and Weber (2011) estimate elasticities using the bunching of retirements around the kinks in the budget set created by discontinuities in pension systems. The small elasticities found by these studies implies that the fraction of individuals who are "at a corner with respect to the decision to retire" (Ljungqvist and Sargent 2011) is quite large in practice.

The mean estimate of the intertemporal substitution elasticity across the six studies in Panel B is 0.32 , only slightly larger than the estimates of steady-state elasticities in Panel A. The similarity between Hicksian and Frisch elasticities is consistent with evidence that income effects are not large enough to produce a substantial difference between intertemporal substitution and steady-state responses. ${ }^{26}$

The elasticity estimates vary across subgroups in correspondence with their mean employment rates, as is well known from prior work (Heckman 1993, Keane and Rogerson 2010).

\footnotetext{
${ }^{25}$ Some of the studies in Panel A of Table 1 do not fully account for income effects and thus obtain estimates that are closer to Marshallian elasticities than Hicksian elasticities. However, we can still conclude from the mean estimates in Panels A and B of Table 1 that the Hicksian elasticity is between 0.25 and 0.32 because the Hicksian is bounded by the Marshallian and Frisch elasticities (MaCurdy 1981).

${ }^{26}$ This does not imply that income effects are small in magnitude. Because the gap between the Frisch and the Hicksian is proportional to the square of the income effect, even sizable income effects $\frac{d[w l]}{d A}$ produce a small gap between the Frisch and Hicksian elasticities; see Chetty (2012) for details.
} 
Groups that have the weakest attachment to the labor force, such as single mothers or older workers near retirement, are the most elastic on the extensive margin (e.g. Meyer and Rosenbaum 2001, Gruber and Wise 1999). Among prime-age males, high rates of labor force participation and low aggregate hours elasticities (which combine the intensive and extensive margins) have led researchers to conclude that the extensive margin response is likely to be quite small (see e.g., Hausman 1985 and Juhn, Murphy, and Topel 1991). This is why most of the studies in Table 1 focus on groups with relatively low participation rates. Hence, the mean extensive margin elasticity in the population as a whole is likely to be below the unweighted mean across the studies in Table 1 of 0.28 .

The heterogeneity in elasticities across subgroups implies that there is no single value of the extensive margin elasticity that can be used across applications. For instance, a recession or tax policy change that affects prime-age males may generate smaller employment responses in the macroeconomy than a change in incentives that affects other groups. The estimates in Table 1 should therefore be interpreted as a rough guide to plausible targets for calibration: they suggest that extensive margin elasticities around 0.25 are reasonable, while values above 1 are not.

\section{Comparing Micro and Macro Estimates}

The micro evidence points to Frisch and Hicksian extensive margin elasticities around 0.25. Does this estimate generate aggregate hours elasticities consistent with macro evidence? The answer to this question depends on the size of intensive margin elasticities because aggregate hours elasticities combine extensive and intensive elasticities. We therefore begin by summarizing the micro and macro evidence on both extensive and intensive margins in Table 2 . The sources and calculations underlying these estimates are described in Appendix C. The rows of Table 2 consider steady-state (Hicksian) vs. intertemporal substitution (Frisch) elasticities, while the columns compare intensive margin (hours conditional on employment) and extensive margin (participation) elasticities. Within each of the four cells, we report micro and macro estimates of the elasticity based on (unweighted) means of existing studies. We also calculate aggregate hours elasticities - the parameter relevant for calibrating representative agent 
models - by summing the extensive and intensive elasticities. ${ }^{27}$

It is important to note that there are wide confidence intervals associated with each of the point estimates in Table 2, as well as ongoing methodological disputes about the validity of some of the underlying studies (see e.g., Saez, Slemrod, and Giertz 2011). Therefore, the estimates should be treated as rough values used to gauge orders of magnitude: differences of 0.1 between elasticity estimates could well be due to noise or choice of specification, while differences of 1 likely reflect fundamental discrepancies. We consider the evidence on steadystate and intertemporal elasticities in turn.

Steady-State. On the extensive margin, our rough estimate of the steady state elasticity from the micro literature is the mean of the estimates in Panel A of Table 1, which is 0.25. On the intensive margin, Chetty (2012) presents a meta-analysis of micro estimates of Hicksian elasticities and reports a mean value of 0.15 (Chetty 2012, Table 1). However, Chetty argues that these elasticities are attenuated by optimization frictions: the small tax changes used to identify micro elasticities do not generate substantial changes in hours because the adjustment costs agents have to pay to change hours outweigh the second-order benefits of reoptimization. Chetty develops a bounding method of recovering the underlying structural elasticity relevant for evaluating the steady-state impacts of taxes. Pooling the 15 studies he analyzes (Table 1, Panels A and B), he obtains a preferred estimate of the structural intensive margin Hicksian elasticity of $0.33 .^{28}$

Macro steady-state estimates are obtained from comparisons across countries with different tax regimes. Nickell (2003) and Davis and Henrekson (2005) find extensive steady-state elasticities of 0.13 and 0.14 , respectively, by regressing log employment-population ratios on log mean net-of-tax rates across countries. Prescott's (2004) tax data coupled with measures of labor force participation rates implies an extensive steady-state elasticity of 0.25 (see Appendix C). Our rough estimate of the steady state extensive margin elasticity from the macro literature

\footnotetext{
${ }^{27}$ For micro studies, this calculation requires that preferences are homogenous across the population. If groups that work few hours have higher extensive elasticities, as suggested by existing evidence, this calculation yields an upper bound on the aggregate hours elasticity (Blundell, Bozio, and Laroque 2011).

${ }^{28}$ Our proposed elasticities of 0.33 on the intensive margin and 0.26 on the extensive margin may appear to contradict the common view that tax changes have smaller short-run effects on the intensive margin than extensive margin. Chetty (2009) argues that the structural intensive margin elasticity relevant for longrun comparisons is larger than the structural extensive margin elasticity once one accounts for frictions. In particular, he shows that frictions attenuate observed extensive margin elasticities much less than intensive margin elasticities because the utility gains from reoptimizing are first-order on the extensive margin and second-order on the intensive margin.
} 
is the mean of the estimates from these three studies, which is 0.17. Davis and Henrekson (2005) estimate a steady-state intensive elasticity of 0.20 by regressing log hours conditional on employment on log net-of-tax rates. As noted above, Prescott's (2004) data produces a steady-state aggregate hours elasticity of 0.7 ; subtracting the extensive margin macro elasticity of 0.25 produced from Prescott's data therefore implies an intensive steady-state elasticity of 0.46. The mean intensive margin elasticity implied by Prescott and Davis and Henrekson's analysis is 0.33 , which we use as our estimate of the macro intensive margin elasticity.

We conclude that micro and macro estimates of steady state aggregate hours elasticities match once one accounts for extensive margin responses and optimization frictions. ${ }^{29}$ Figure 2a illustrates the agreement by plotting log of hours per adult vs. log net-of-tax rates using the same cross-country data as Prescott (2004). The solid green line shows the best fit to Prescott's data, which generates a Hicksian elasticity of 0.7 as noted in Section 2. The dashed red line shows the relationship predicted by our preferred estimate of the micro aggregate hours elasticity of 0.58 from Table 2 (with the intercept chosen to match the mean values in the data). The similarity of the two lines illustrates the concordance between micro and macro estimates of steady-state elasticities.

Intertemporal Substitution. On the extensive margin, our preferred micro estimate of the intertemporal elasticity is the mean of the estimates in Panel B of Table 1, which is 0.32. On the intensive margin, there is less quasi-experimental evidence on intertemporal substitution elasticities. Bianchi et al. (2001) find an intensive-margin elasticity from the Iceland reform of 0.37 (see Chetty (2012) for the elasticity calculation using Bianchi et al.'s estimates). Pistaferri (2003) reports a Frisch intensive elasticity of 0.7 using microdata on expectations about wages. The mean of these two estimates is 0.54 . It is not surprising that these estimates of the intensive Frisch elasticity are only slightly larger than our preferred estimate of the intensive Hicksian elasticity of 0.33. Chetty (2012) shows that the Frisch elasticity must be less than 0.47 given a Hicksian elasticity of 0.33 in an intensive-margin model with balanced growth and an intertemporal elasticity of substitution of consumption below 1. Utility specifications that generate a Frisch elasticity that is much larger than the

\footnotetext{
${ }^{29}$ The similarity between micro and macro estimates may be surprising given the institutional and regulatory differences across countries (Alesina, Glaeser, and Sacerdote 2005). However, institutions and regulations can partly be interpreted as sources of optimization frictions, which we account for using Chetty's (2009) bounding procedure.
} 
Hicksian elasticity are inconsistent with micro estimates of income effects and elasticities of intertemporal substitution of consumption.

Equilibrium macro models identify intertemporal substitution labor supply elasticities from fluctuations in hours over the business cycle. Most macro studies calibrate representative agent models and therefore report only intertemporal elasticities of aggregate hours. The intertemporal aggregate hours elasticity required to match business cycle data ranges from 2.6 to 4 in real business cycle models (Cho and Cooley 1994, Table 1; King and Rebelo 1999, p975). Table 2 reports the mean intertemporal aggregate hours elasticities implied by these numbers, 3.31..$^{30}$ Micro estimates imply a Frisch elasticity of aggregate hours of 0.86 , well below the values implied by RBC models.

The few available decompositions of macro aggregate hours elasticities into extensive and intensive margins suggest that macro estimates are roughly in alignment with micro estimates on the intensive margin. Business cycle fluctuations in hours conditional on employment account for only $1 / 6$ of the fluctuations in aggregate hours at an annual level (Heckman 1984). Given that elasticities of 2.6 to 4 fit the fluctuations in aggregate hours, we infer that intensive Frisch elasticities around 0.43 to 0.66 would match macro evidence in RBC models. These values are modestly larger than the intensive intertemporal elasticity of 0.5 implied by micro evidence.

In contrast, macro evidence sharply contradicts micro estimates of the extensive intertemporal elasticity. The fact that employment fluctuations account for $5 / 6$ of the fluctuation in aggregate hours suggests that extensive elasticities of 2.18 to 3.33 would be needed to match the data in standard RBC models. ${ }^{31}$ If the RBC models considered in Table 2 were calibrated to match an intensive intertemporal elasticity of 0.54 , they would require extensive intertemporal elasticities of 3.31-0.54 $=2.77$ on average to match aggregate hours fluctuations. This value is an order of magnitude larger than all of the micro estimates in Table 1.

\footnotetext{
${ }^{30}$ An earlier version of this table (Chetty et al. 2011b) included an estimate 1.92 from Smets and Wouters (2007) when computing the macro estimate of the intertemporal substitution elasticity. While Smets and Wouters report an estimate of 1.92 , in personal correspondence they noted that the correct elasticity implied by their model is the reciprocal of the reported estimate, $\frac{1}{1.92}=0.52$. This elasticity is much lower than traditional models because of a large number of frictions including wage and price rigidities, which make the Smets and Wouters paper significantly different from the pure equilibrium macro models discussed here. We thank Susan Yang for pointing out this correction.

${ }^{31}$ Cho and Cooley (1994) decompose the aggregate hours elasticity in their RBC model into intensive and extensive margins using a different methodology. Their analysis generates an extensive Frisch elasticity of 1.61 .
} 
We conclude that extensive labor supply responses are not large enough to explain observed fluctuations in employment rates at business cycle frequencies. This result is illustrated in Figure 2b. The solid blue line in the figure shows fluctuations in employment rates over the business cycle in the U.S. It plots the log deviation of employment (measured using household surveys) from a Hodrick-Prescott filtered trend. The dashed red line shows predicted employment fluctuations due to labor supply using our preferred micro estimate of the extensive margin Frisch elasticity of 0.32 . The prediction is constructed by multiplying the Frisch elasticity of 0.32 by log deviations in real wages from a Hodrick-Prescott filtered trend. The fluctuations in the data are much larger than the prediction based on micro evidence, illustrating that fluctuations in labor supply account for only a small share of observed employment fluctuations over the business cycle.

The size of the fluctuations in the micro prediction may be attenuated because of composition bias in the BLS wage series. Barsky, Solon and Parker (1994) argue that actual wages are approximately twice as volatile as observed wages because of changes in the composition of employed workers. With this adjustment, one would need an aggregate hours elasticity of $3.31 / 2=1.66$ to fit the macro data. While accounting for composition bias helps reduce the gap substantially, it does not fully reconcile the discrepancy between the macro business cycle data and predictions based on micro evidence.

Heterogeneity. As emphasized by Dyrda et al. (2012), macro models may not exactly match micro evidence on the extensive margin because of heterogeneity in elasticities across subgroups. However, observable heterogeneity in elasticities if anything reinforces the main conclusions drawn above. The heterogeneity in extensive margin responses across groups documented in Table 1 mirrors the heterogeneity observed in extensive margin responses when comparing steady-state behavior across countries with different tax regimes. In particular, individuals near retirement and secondary earners exhibit the largest differences in employment rates across countries with different tax systems (Rogerson and Wallenius 2007, Blundell, Bozio, and Laroque 2011).

In contrast, heterogeneity amplifies the discrepancy between micro and macro estimates of intertemporal substitution elasticities. Employment rates fluctuate substantially over the business cycle even for this subgroup (Clark and Summers 1981, Jaimovich and Siu 2009). This is illustrated by the dashed black series in Figure 2b, which plots detrended employment 
for males aged 25-55. Fluctuations in employment for prime age males are very similar to those for the population as a whole. However, microeconomic studies clearly show that extensive margin elasticities are near zero for prime-age males. The sharp divergence between micro and macro Frisch elasticities within this subgroup reinforces our conclusion that indivisible labor supply cannot fully account for the fluctuations in aggregate hours over the business cycle. $^{32}$

\section{Conclusion}

Indivisible labor is a central feature of many modern macroeconomic models that seek to explain aggregate fluctuations in labor utilization using labor supply. From a qualitative perspective, microeconometric evidence strongly supports the importance of indivisible labor: changes in wage rates clearly induce extensive-margin responses. From a quantitative perspective, observed extensive margin responses are adequate to explain the gap between micro and macro estimates of steady-state elasticities when combined with factors such as frictions. However, extensive margin labor supply responses are not large enough to explain the gap between micro and macro estimates of intertemporal substitution elasticities. Consequently, explanations of the business cycle based on changes in labor supply can only partly explain fluctuations in hours over the business cycle.

One interpretation of our analysis is that it points in favor of recent macro models that feature a cyclical "labor wedge" between the marginal rate of substitution of consumption for leisure and the marginal product of labor. The micro evidence reviewed here is consistent with macro evidence that labor wedges are substantial (Chari et al 2007; Shimer, 2009). Our conclusion that labor supply is important but cannot entirely account for fluctuations over the business cycle supports models that combine a labor supply margin with other sources of fluctuations. For instance, Hall (2009) shows that a search-and-matching-generated unemployment margin combined with a labor supply margin can match observed fluctuations

\footnotetext{
${ }^{32}$ Fluctuations in wage rates for prime age males are very similar to those for the population as a whole at business cycle frequencies. To illustrate this, we use CPS data on median usual weekly earnings for full time employed wage and salary workers from the Bureau of Labor Statistics (series LEU0252881500) and men aged 25-54 (series LEU0252888100), available from 2000 to 2011. We adjust for inflation using the CPI provided by the BLS aggregated to a quarterly frequency and HP filter the logs of the CPI-adjusted wage series with a smoothing parameter of 1600 . The resulting standard deviation of log real wages around the HP filtered trend is .0122 for the full population and .0123 for prime aged men.
} 
in employment rates over the business cycle without requiring large extensive margin labor supply responses. ${ }^{33}$ Models that generate unemployment by taking individuals off their labor supply curve in the short run, e.g. due to wage rigidities, are also consistent with our results. While our analysis does not distinguish between alternative explanations of the labor wedge, our estimates could be used to calibrate the labor supply component of models that seek to explain aggregate fluctuations with labor wedges.

Based on our reading of the micro evidence, we recommend calibrating macro models to match Hicksian elasticities of 0.3 on the intensive and 0.25 on the extensive margin and Frisch elasticities of 0.5 on the intensive and 0.25 on the extensive margin. ${ }^{34,35}$ These elasticities are consistent with the observed differences in aggregate hours across countries with different tax systems. They also match the relatively small fluctuations in hours conditional on employment over the business cycle. The remaining challenge is to formulate models that fit the large fluctuations in employment rates over the business cycle when calibrated to match an extensive margin labor supply elasticity of 0.25. Even with indivisible labor, models that require a Frisch elasticity of aggregate hours above 1 are inconsistent with micro evidence.

\footnotetext{
${ }^{33}$ In Hall's model, workers choose both hours and employment based on both standard labor supply factors and the time and effort needed to find a job as in a Diamond-Mortensen-Pissarides model with rigid wages. These forces generate an aggregate hours elasticity of 1.9 even with an intensive Frisch elasticity of 0.7.

${ }^{34}$ That is, one should choose a reservation wage distribution such that a $10 \%$ increase in the net-of-tax wage leads to a $2.5 \%$ increase in employment rates. More generally, simulating quasi-experiments such as the tax policy changes analyzed here would be a simple way to evaluate which macro models are consistent with micro data.

${ }^{35}$ We suspect that this estimate is, if anything, biased upward for two reasons: (1) the mean extensive margin elasticity for the population as a whole is less than 0.25 as noted above and (2) publication bias drives micro studies toward reporting higher elasticity estimates (Card and Krueger 1995).
} 
References

Alesina, Alberto, Edward Glaeser, and Bruce Sacerdote. 2005. "Work and Leisure in the US and Europe: Why So Different?" In NBER Macroeconomics Annual, ed. Mark Gertler and Kenneth Rogoff. Cambridge MA: MIT Press.

Altonji, Joseph.G. 1986. "Intertemporal Substitution in Labor Supply: Evidence from Micro Data." Journal of Political Economy, 94: S176-S215.

Angrist, Joshua D. 1991. "Grouped-Data Estimation and Testing in Simple Labor-Supply Models." Journal of Econometrics, 47: 243-66.

Ashenfelter, Orley. 1984. "Macroeconomic Analyses and Microeconomic Analyses of Labor Supply." Carnegie-Rochester Conference Series on Public Policy, 21: 117-56.

Auerbach, Alan J. 1985. "The Theory of Excess Burden and Optimal Taxation." In The Handbook of Public Economics, ed. Alan J. Auerbach and Martin Feldstein, 61-124, Amsterdam: Elsevier.

Barsky, Robert, Gary Solon, and Jonathan A. Parker. 1994. "Measuring the Cyclicality of Real Wages: How Important is Composition Bias." Quarterly Journal of Economics, 109(1): 1-25.

Bianchi, Marco, Björn R. Gudmundsson, and Gylfi Zoega. 2001. "Iceland's Natural Experiment in Supply-Side Economics." American Economic Review, 91(5): 1564-79.

Blundell, Richard, Antoine Bozio, and Guy Laroque. 2011. "Labour Supply Responses and the Extensive Margin: The US, UK and France."

Blundell, Richard, and Thomas MaCurdy. 1999. "Labor Supply: A Review of Alternative Approaches." In Handbook of Labor Economics, ed. Orley Ashenfelter and David Card, 1559-695, Amsterdam: Elsevier Science/North-Holland.

Brown, Kristine M. 2009. "The Link between Pensions and Retirement Timing: Lessons from California Teachers." http://www.ilir.uiuc.edu/brown/CalstrsRetire_Brown.pdf.

Browning, Martin. 2005. "A Working Paper from April 1985: Which Demand Elasticity Do We Know and Which Do We Need to Know for Policy Analysis?" Research in Economics, 59(4): 293-320.

Browning, Martin, Lars Peter Hansen, and James J. Heckman. 1999. "Micro data and General Equilibrium Models." In Handbook of Macroeconomics, ed. John B. Taylor, Michael Woodford, 543-633. Amsterdam: Elsevier/North-Holland.

Card, David. 1990. "Labor Supply with a Minimum Hours Threshold." Carnegie-Rochester Conference Series on Public Policy 33: 137-168.

Card, David, and Alan B. Krueger. 1995. "Time-Series Minimum-Wage Studies: A Meta-Analysis." American Economic Review, 85(2): 238-243.

Card, David, and Dean R. Hyslop. 2005. "Estimating the Effects of a Time-Limited Earnings Subsidy for Welfare-Leavers." Econometrica, 73(6): 1723-70.

Carrington, William J. 1996. "The Alaskan Labor Market During the Pipeline Era." Journal of Political Economy, 104(1): 186-218. 
Chang, Yongsung, and Sun-Bin Kim. 2006. "From Individual to Aggregate Labor Supply: A Quantitative Analysis Based on a Heterogeneous Agent Macroeconomy." International Economic Review, 47(1): 1-27.

Chari, V. V., Patrick J. Kehoe, and Ellen R. McGrattan. 2007. "Business Cycle Accounting." Econometrica, 75(3): 781-836.

Chetty, Raj. 2012. "Bounds on Elasticities with Optimization Frictions: A Synthesis of Micro and Macro Evidence on Labor Supply." Econometrica 80(3): 969-1018.

Chetty, Raj, John N. Friedman, Tore Olsen, and Luigi Pistaferri. 2011a. "Adjustment Costs, Firm Responses, and Micro vs. Macro Labor Supply Elasticities: Evidence from Danish Tax Records." Quarterly Journal of Economics, 126(2): 749-804.

Chetty, Raj, Adam Guren, Day Manoli, and Andrea Weber. 2011b. "Are Micro and Macro Labor Supply Elasticities Consistent? A Review of Evidence on the Intensive and Extensive Margins." American Economic Review, 101(3): 471-5.

Cho, Jang-Ok, and Thomas F. Cooley. 1994. "Employment and Hours Over the Business Cycle." Journal of Economic Dynamics and Control, 18(2): 411-32.

Cho, Jang-Ok, and Richard Rogerson. 1988. "Family Labor Supply and Aggregate Fluctuations." Journal of Monetary Economics, 21(2-3): 233-45.

Christiano, Lawrence and Martin Eichenbaum. 1992. "Current Real-Business-Cycle Theories and Aggregate Labor-Market Fluctuations." American Economic Review, 82(3): 43050 .

Clark, Kim B., and Lawrence H. Summers 1981. "The Demographic Composition of Cyclical Employment Variations." Journal of Human Resources, 16(1): 61-79.

Davis, Steven J., and Magnus Henrekson. 2005. "Tax Effects on Work Activity, Industry Mix and Shadow Economy Size: Evidence from Rich-Country Comparisons." In Labour Supply and Incentives to Work in Europe, ed. Ramón Gómez Salvador, Ana Lamo, Barbara Petrongolo, Melanie Ward, and Etienne Wasmer, 44-104. Northamption, MA: Edward Elgar Press.

Devereux, Paul J. 2004. "Changes in Relative Wages and Family Labor Supply." Journal of Human Resources, 39(3): 698-722.

Domeij, David, and Martin Floden. 2006. "The Labor-Supply Elasticity and Borrowing Constraints: Why Estimates Are Biased." Review of Economic Dynamics. 9(2): 242-62.

Dyrda, Sebastian, Greg Kaplan, and José-Víctor Ríos-Rull. 2012. "Business Cycles and Household Formation: The Micro vs the Macro Labor Elasticity." NBER Working Paper 17880 .

Eckstein, Zvi, and Kenneth I. Wolpin. 1989. "Dynamic Labour Force Participation of Married Women and Endogenous Work Experience." Review of Economic Studies, 56(3): 375-390.

Eissa, Nada, and Hilary Williamson Hoynes. 2004. "Taxes and the Labor Market Participation of Married Couples: The Earned Income Tax Credit." Journal of Public Economics, 88(9-10): 1931-58. 
Eissa, Nada, and Jeffrey B. Liebman. 1996. "Labor Supply Response to the Earned Income Tax Credit." The Quarterly Journal of Economics, 111(2): 605-37.

Gourio, François, and Pierre-Alexandre Noual. 2009. "The Marginal Worker and the Aggregate Elasticity of Labor Supply." http://people.bu.edu/fgourio/margworker1106.pdf.

Graversen, Ebbe Krogh. 1998. "Labor Supply and Work Incentives." PhD diss., University of Aarhus.

Gruber, Jonathan and David A. Wise. 1999. "Introduction and Summary." In Social Security and Retirement Around the World, eds. Jonathan Gruber and David A. Wise, 1-35. University of Chicago Press.

Hall, Robert E. 2009. "Reconciling Cyclical Movements in the Marginal Value of Time and the Marginal Product of Labor." Journal of Political Economy, 117(2): 281-323.

Hansen, Gary D. 1985. "Indivisible Labor and the Business Cycle." Journal of Monetary Economics. 16(3): 309-327.

Hausman, Jerry. 1985. "Taxes and Labor Supply." In , ed. Alan Auerbach and Martin Feldstein, 213-63. Handbook of Public Economics Vol I. Amsterdam: North-Holland.

Heckman, James J. 1984. "Comments on the Ashenfelter and Kydland Papers." CarnegieRochester Conference Series on Public Policy, 21: 209-24.

Heckman, James J. 1993. "What Has Been Learned About Labor Supply in the Past Twenty Years?" American Economic Review, 83(2): 116-21.

Heckman, James J. and Mark R. Killingsworth. 1987. "Female labor supply: A survey." In Handbook of Labor Economics, eds. O. Ashenfelter and R. Layard, 103-204, Amsterdam: Elsevier.

Holtz-Eakin, Douglas, David Joulfaian, and Harvey S. Rosen. 1993. "The Carnegie Conjecture: Some Empirical Evidence," Quarterly Journal of Economics, 108(2): 413-35.

Imai, Susumu, and Michael Keane. 2004. "Intertemporal Labor Supply and Human Capital Accumulation." International Economic Review, 45(2):601-42.

Imbens, Guido W., Donald B. Rubin, and Bruce I. Sacerdote. 2001. "Estimating the Effect of Unearned Income on Labor Earnings, Savings, and Consumption: Evidence from a Survey of Lottery Players." The American Economic Review. 91(4): 778-94.

Jacob, Brian A. and Jens Ludwig. 2008. "The Effects of Housing Assistance on Labor Supply: Evidence from a Voucher Lottery" NBER Working Paper 14570.

Jaimovich, Nir, and Henry E. Siu. 2009. "The Young, the Old, and the Restless: Demographics and Business Cycle Volatility" American Economic Review, 99(3): 804-26.

Juhn, Chinhui, Kevin M. Murphy, and Robert H. Topel. 1991. "Why Has the Natural Rate of Unemployment Increased over Time?" In Brookings Papers of Economic Activity, ed. William C. Brainard and George L. Perry, 75-142. Washington, DC: The Brookings Institution.

Keane, Michael P. 2010. "Labor Supply and Taxes: A Survey." University of Technology, Sydney Working Paper 160.

Keane, Michael P., and Richard Rogerson. 2010. "Reconciling Micro and Macro Labor Supply Elasticities." Unpublished. 
King, Robert G., and Sergio T. Rebelo. 1999. "Resuscitating Real Business Cycles." In Handbook of Macroeconomics, ed. John B. Taylor and Michael Woodford, 927-1007. Amsterdam: North-Holland.

Kimmel, Jean and Thomas J. Kniesner. 1998. "New Evidence on Labor Supply: Employment Versus Hours Elasticities by Sex and Marital Status." Journal of Monetary Economics. 42(2): 289-301.

Liebman, Jeffrey, and Emmanuel Saez. 2006. "Earnings Responses to Increases in Payroll Taxes." http://elsa.berkeley.edu/ saez/liebman-saezSSA06.pdf.

Lin, Winston, Philip K. Robins, David Card, Kristen Harknett, and Susanna LuiGurr. 1998. "When Financial Incentives Encourage Work: Complete 18-Month Findings from Self-Sufficiency Project." Ottawa: Social Research and Demonstration Corporation.

Ljungqvist, Lars, and Thomas J. Sargent. 2006. "Do Taxes Explain European Employment? Indivisible Labor, Human Capital, Lotteries, and Savings." In NBER Macroeconomics Annual 2006, ed. Daron Acemoglu, Kenneth Rogoff, and Michael Woodford, 181-246. Cambridge, MA: MIT Press.

Ljungqvist, Lars, and Thomas J. Sargent. 2011. "A Labor Supply Elasticity Accord?" American Economic Review, 101(3): 478-91.

Low, Hamish. 2005. "Self-Insurance in a Life-Cycle Model of Labor Supply and Savings." Review of Economic Dynamics. 8(4): 945-75.

MaCurdy, Thomas E. 1981. "An Empirical Model of Labor Supply in a Life-Cycle Setting." Journal of Political Economy. 89(6): 1059-85.

Manoli, Dayanand, and Andrea Weber. 2011. "Nonparametric Evidence on the Effects of Retirement Benefits on Labor Force Participation Decisions."

Meghir, Costas, and David Phillips. 2010. "Labor Supply and Taxes," In Dimensions of Tax Design. ed. The Mirrlees Review, 202-74. Oxford: Oxford University Press.

Meyer, Bruce D. 2010. "The Effects of the Earned Income Tax Credit and Recent Reforms." In Tax Policy and the Economy, ed. J.M. Poterba, 153-80. MIT Press: Cambridge, MA.

Meyer, Bruce D., and Dan T. Rosenbaum. 2000. "Making Single Mothers Work: Recent Tax and Welfare Policy and its Effects." National Tax Journal, 53(4): 1027-59.

Meyer, Bruce D., and Dan T. Rosenbaum. 2001. "Welfare, the Earned Income Tax Credit, and the Labor Supply of Single Mothers." The Quarterly Journal of Economics, 116(3): 1063-114.

Mulligan, Casey. 2001. "Aggregate Implications of Indivisible labor." Advances in Macroeconomics 1(1).

Nickell, Steven. 2003. "Employment and Taxes." CESifo Working Paper 1109.

Pistaferri, Luigi. 2003. "Anticipated and Unanticipated Wage Changes, Wage Risk, and Intertemporal Labor Supply." Journal of Labor Economics, 21(3): 729-54.

Prescott, Edward. 2004. "Why Do Americans Work So Much More Than Europeans?" Federal Reserve Bank of Minneapolis Quarterly Review, 28(1): 2-13.

Prescott, Edward, Richard Rogerson, and Johanna Wallenius. 2009. "Lifetime Aggregate Labor Supply with Endogenous Workweek Length." Review of Economic Dynamics, 
12(1): 23-36.

Rogerson, Richard. 1988. "Indivisible Labor, Lotteries and Equilibrium." Journal of Monetary Economics, 21(1): 3-16.

Rogerson, Richard, and Johanna Wallenius. 2007. "Micro and Macro Elasticities in a Life Cycle Model with Taxes." National Bureau of Economic Research Working Paper No. 13017.

Rogerson, Richard, and Johanna Wallenius. 2009. "Micro and Macro Elasticities in a Life Cycle Model with Taxes." Journal of Economic Theory, 144(6): 2277-92.

Saez, Emmanuel, Joel Slemrod, and Seth Giertz. 2011. "The Elasticity of Taxable Income with Respect to Marginal Tax Rates: A Critical Review." Forthcoming, Journal of Economic Literature.

Shimer, Robert. 2009. "Convergence in Macroeconomics: The Labor Wedge." American Economic Journal: Macroeconomics. 1(1): 280-297.

Smets, Frank, and Rafael Wouters. 2007. "Shocks and Frictions in US Business Cycle: A Bayesian DSGE Approach." American Economic Review. 97(3): 586-606.

Trabandt, Mathias and Harold Uhlig. 2009. "How Far Are We From The Slippery Slope? The Laffer Curve Revisited." NBER Working Paper No.15343.

Ziliak, James P., and Thomas J. Kniesner. 1999. "Estimating Life Cycle Labor Supply Tax Effects." The Journal of Political Economy. 107(2): 326-59. 


\section{Appendix A. Simulations of Quasi-Experiments (Figure 1)}

This appendix describes the simulations of three quasi-experiments in the Rogerson and Wallenius (2009) model and the robustness of the simulations to alternative assumptions about the intensive margin labor supply elasticity. The technical appendix describes the analytic solution method in detail.

Calibration. The target values used to calibrate the model's parameters $\left\{\alpha, e_{1}, \bar{h}, \gamma\right\}$ are described in the main text. In choosing the fraction of life worked $(f)$ for the calibration, we use the frequency at which employment is measured in the data. For instance, in the EITC simulation we calculate labor force participation in a given year as whether an individual worked at all in the past year to match the annual employment observation CPS. Because of this, the fraction of life worked at any given instant $(f)$ differs slightly from the stated target value. To calibrate $\left\{\alpha, e_{1}, \bar{h}, \gamma\right\}$, we set $\gamma=\frac{1}{\varepsilon_{\mathrm{INT}}}$ to match the target for the intensive Frisch elasticity. We then calibrate the remaining parameters using the model's equilibrium conditions. Finally, we manually adjust $e_{1}$ to match $w_{R} / w_{\max }$, following RW.

Experiment 1: Tax Holiday in Iceland. Bianchi et al.'s data is the ratio of the total number of weeks worked to the potential supply of weeks that could have been worked by all working-age individuals in a given calendar year. We define labor force participation by whether a generation works in a given week. We then average across weeks for each calendar year to get an annual measure comparable to Bianchi et al.'s data. With $\varepsilon_{I N T}=.5$, $f=79.2 \%, h_{\max }=.45$, and $w_{R} / w_{\max }=1 / 2$, the calibrated values are $\gamma=2, \bar{h}=.384$, $\alpha=10.106$, and $e_{1}=.593$. These parameter values generate a Frisch aggregate hours elasticity of 2.085 and a Frisch labor force participation elasticity of 1.773. These and all subsequent reported Frisch elasticities are calculated by simulating a temporary, small tax change using the same methodology as the Iceland and Canada SSP simulations; see the technical appendix for details. The parameter values generate a compensated aggregate hours elasticity of .663, a compensated labor force participation elasticity of .577, and a compensated intensive margin hours elasticity of .144. These and all subsequent reported compensated elasticities are calculated by comparing the steady state change in response to a small tax change; see the technical appendix for details. After the tax change, the maximum hours worked over the life cycle are .737 and the minimum hours worked are .570 .

Experiment 2: SSP Welfare Demonstration in Canada. We generate the effective tax rates for the treatment and control groups of the SSP welfare demonstration in Canada using information on the hypothetical income of the average individual in the treatment group from Lin et al. (1998). Lin et al. use a wage regression to estimate that the predicted wage of the average individual in the treatment group is $\$ 6.24$ per hour for individuals in British Columbia and $\$ 5.53$ per hour for individuals in New Brunswick. Lin et al. then present in Table G.2 an itemized calculation of the average treatment group individual's income accounting for taxes and other transfers under the SSP subsidy and for an individual on the standard Income Assistance (IA) welfare program. This is called hypothetical income because they use the hourly wage rate and assume the individual works 30 hours per week for 52 weeks per year in both cases.

Using this calculation, in New Brunswick an individual receiving the SSP subsidy would make $\$ 20,184$ per year net of taxes and transfers, while an individual working and receiving IA would make $\$ 14,847$ per year. If the individual did not work at all and took IA, they would not realize their earnings of $\$ 8,627$ but would have an IA payment that is $\$ 6,117$ higher. This 
reflects the almost dollar-for-dollar reduction of welfare payments of earnings above $\$ 2,400$. The individual's income would have been $\$ 12,337$ if they had not worked. The additional income from working 1,560 hours per year is thus $\$ 2,510$ for an individual on IA and $\$ 7,847$ for an individual receiving the SSP subsidy. This implies an hourly wage rate of $\$ 1.61$ on IA and an effective tax rate of $70.9 \%$ under IA. Under SSP, however, the hourly wage rate is $\$ 5.03$ and the effective tax rate is $9.04 \%$.

Similarly, for an individual in British Columbia, an individual receiving the SSP subsidy would make $\$ 28,267$ per year net of taxes and transfers, while an individual working and receiving IA would make $\$ 23,078$ per year. If the individual did not work at all and took IA, they would not realize their earnings of $\$ 9,734$ but would have an IA payment that is $\$ 7,557$ higher. The individual's income would have been $\$ 20,901$ if they had not worked. The additional income from working 1,560 hours per year is thus $\$ 2,177$ for an individual on IA and $\$ 7,366$ for an individual receiving the SSP subsidy. This implies an hourly wage rate of $\$ 1.40$ on IA and an effective tax rate of $77.6 \%$ under IA. Under SSP, however, the hourly wage rate is $\$ 4.72$ and the effective tax rate is $24.3 \%$.

Averaging the British Columbia and New Brunswick results together (as roughly half the sample resides in each area), an average single parent with one child in the control group faced effective average tax rates of $74.3 \%$ when moving from no work to full-time work at the minimum wage. An average individual in the treatment group faced effective average tax rates of $16.7 \%$ for the same change.

Card and Hyslop observe employment rates at a monthly frequency for 53 months starting from the month of random assignment. To replicate this data as closely as possible, we define labor force participation by whether a generation works in a given month. Generating $w_{R} / w_{\max }=1 / 2$ would require $e_{1}<0$. We therefore set $e_{1}=0$, generating $w_{R} / w_{\max }=.615$. With $\varepsilon_{I N T}=.5, f=23.25 \%$, and $h_{\max }=.45$, the calibrated values are $\gamma=2, \bar{h}=.263$, and $\alpha=38.378$. These parameter values generate a Frisch aggregate hours elasticity of 3.294 and a participation Frisch elasticity of 3.016. The compensated aggregate hours elasticity is .765 , the compensated participation elasticity is .705, and the compensated intensive margin hours elasticity is .109. After the tax change, the maximum hours worked are .746 and the minimum hours worked are .394 .

Finally, the vast majority of individuals in the SSP sample were between the ages of 16 and 46, corresponding to the first half of life in our model. Consequently, in our simulation we only consider individuals in the first half of their life, corresponding to ages 16 to 46 out of a 60-year working life from 16 to 76.

Experiment 3: Earned Income Tax Credit in the U.S. The effective tax rates for the 1994 EITC expansion come from Meyer and Rosenbaum (2000), Table 2: the gain from working for a single mother, which includes changes in wages, welfare, Medicaid, and taxes as a result of the labor supply decision, was $\$ 8,943$ in 1992 and $\$ 10,245$ in 1996 . This is relative to wages of $\$ 18,165$, generating effective tax rates of $50.8 \%$ in 1992 to $43.6 \%$ in 1996 .

Meyer (2010) observes employment rates at an annual level using CPS data. To adjust for observables and secular time trends, Meyer regresses employment rates on observables, year dummies, and year $\times$ number of children dummies and plots the coefficients on the year $\times$ number of children dummies in Figure 2. We plot the difference between the no children dummies and a weighted average of the one child and two child dummies, using the weights reported in Table 6 of Meyer (2010). We then add the difference between the dummies and raw labor force participation rates for one- and two-child mothers to arrive at the series plotted 
in Figure 1c.

To replicate the data as closely as possible, in the simulations we define labor force participation by whether a generation works in a given month. Because of this, we use a target value of $f=.758$ rather than $f=.791$ as in the data. With $f=.758$ at each instant, the fraction of individuals working in each year before the quasi-experiment is approximately $79.1 \%$. Because most single mothers are under 45 , in our simulation we only consider individuals in the first half of their life, corresponding to simulated ages of 16 to 46 out of a 60 -year simulated working life from 16 to 76 .

With $\varepsilon_{I N T}=.5, f=68.7 \%, h_{\max }=.45$, and $w_{R} / w_{\max }=1 / 2$, the calibrated values are $\gamma=2, \bar{h}=.247, \alpha=22.871$, and $e_{1}=.574$. These parameter values generate a Frisch aggregate hours elasticity of 2.125 and a Frisch participation elasticity of 1.814 . The compensated aggregate hours elasticity is .691, the compensated participation elasticity is .608, and the compensated intensive margin hours elasticity is .144. Maximum hours worked after the tax change are .460 and minimum hours worked are .370 .

Robustness. We now evaluate the robustness of the results to calibrating to an intensive margin Frisch elasticity of $\varepsilon_{\mathrm{INT}}=.25$.

For the Iceland simulation, the calibrated values are $\gamma=4, \bar{h}=.509$, and $\alpha=32.861$. These parameter values generate a Frisch aggregate hours elasticity of 1.897 and a Frisch participation elasticity of 1.738. With these parameters, labor force participation jumps $13.3 \%$, rather than $13.5 \%$ as presented in the main text. Maximum hours worked after the tax change are .719 and minimum hours worked are .636.

For the Canada SSP simulation, the calibrated values are $\gamma=4, \bar{h}=.337$, and $\alpha=306.149$. As above we set $e_{1}=0$, which generates $w_{R} / w_{\max }=.611$. These parameter values generate a Frisch aggregate hours elasticity of 3.089 and a participation Frisch elasticity of 2.949. With these parameters, labor force participation jumps from $23.5 \%$ to $76.3 \%$ one year after the subsidy is introduced. After the tax change, maximum hours worked are .585 and minimum hours worked are .421 .

For the U.S. EITC simulation, the calibrated values are $\gamma=4, \bar{h}=.327, \alpha=179.957$, and $e_{1}=.581$. These parameter values generate a Frisch aggregate hours elasticity of 1.647 and a participation Frisch elasticity of 1.475 . With these parameters, labor force participation jumps from $79.1 \%$ to $85.5 \%$ on impact and then rises to $85.7 \%$ over the next 4 years. Maximum hours after the tax change are .455 and minimum hours are .409 .

Calibrating to a smaller intensive Frisch elasticity of $\varepsilon_{\mathrm{INT}}=.25$ thus does not change our conclusions: the RW model over-predicts the impacts of the temporary changes in Iceland and Canada by an order of magnitude, but is closer to matching the steady-state impact of the EITC permanent tax change.

\section{Appendix B. Meta-Analysis of Quasi-Experimental Estimates (Table 1)}

This appendix describes how the participation elasticities and standard errors in columns 2 and 3 of Table 1 are calculated. We report standard errors based directly on the authors' estimates if available; if not, we use the delta method to calculate a standard error for the numerator of the elasticity (log employment changes) based on reported standard errors for employment effects. If information necessary for the delta method is missing, we approximate the standard error by assuming the T-statistic on the elasticity would be the same as the T-statistic on the author's estimate. 
1. Juhn, Murphy, and Topel (1991): The partial elasticity is computed by taking a weighted average of the estimates in column (3) of Table 9; the weights are computed as the fraction of the population represented by each estimate using the wage percentiles listed in column (1) of Table 9. We normalize this partial elasticity by the mean of the employment rate from 1970-89 using one minus the non-employment values reported in column (3) of Table 1. Participation is defined at the weekly level (by the fraction of weeks worked in the year). For the standard error, the variance of the partial elasticity is computed as a weighted average of the variances of the estimates in column (3) of Table 9 using the T-statistics reported in the same column. We normalize this standard error using the mean of one minus the non-employment values reported in column (3) of Table 1, assuming that non-employment is measured without error.

2. Eissa and Liebman (1996): The percentage change in participation is reported in Table III, column (4) as $2.8 \%$ with a standard error of $0.9 \%$. The participation rate of single mothers is reported in Table II, column (1) as $73 \%$ with a standard error of $0.4 \%$. The percentage change in net earnings for the same data source is reported by Meyer and Rosenbaum (2000), Table 2, as the financial gain from working for single mothers in $1990(\$ 8,458)$ relative to the gain from working in $1984(\$ 7,469)$. The elasticity is thus calculated as $(\log (0.73+0.028)$ $\log (0.73)) /(\log (8458)-\log (7469))$. Participation is defined as positive work hours in the past calendar year. For the standard error, the delta method is used with the additional assumption that the financial gain in the denominator, for which there is no reported standard error, is measured without error.

3. Graversen (1998): Table 5, elasticity of participation rate with respect to after tax wage, average of the four reported estimates for married women and single women, bottom panel, columns (1) and (4). The author only reports standard errors on the differences-in-differences estimates in Table 4 used to calculate the elasticities in Table 5. Because complete estimates are unavailable, we approximate the standard error of each of the four reported estimates by assuming that the T-statistics on the differences-in-difference estimates are the same as the T-statistic on the elasticities. We then average the four estimates as above to get the final reported standard error.

4. Meyer and Rosenbaum (2001): On page 1092, an elasticity of 1.07 for any employment (positive work hours) during the year is reported using gross earnings of single mothers as the base level of earnings. However, the correct denominator to calculate the percentage wage increase is net earnings prior to the reform after accounting for taxes and transfers. Making the correction requires multiplying the reported elasticity by the ratio of net earnings to gross earnings prior to the reform. Meyer and Rosenbaum (2000, page 1043) report that this ratio is $7270 / 18165$, and thus the percentage increase in the wage is actually $45 \%$ rather than the $18 \%$ assumed to calculate the elasticity reported in Meyer and Rosenbaum (2000). The corrected elasticity estimate is given by $1.07 \times 7270 / 18165=0.43$. For the standard error, we recreate the numerator used in the calculation of the 1.07 elasticity as described by the authors on page 1091. The change in participation rate comes from the estimate in row (1), column (5) of Table 4. Base participation in 1984 and its standard error are calculated using weighted average of columns 6 and 7 of the first row of Table 2 with the weights calculated from number of observations reported in the last row of column 1 and 2 in Appendix 2. An estimate of the elasticity numerator's standard error is then calculated using the delta method. Assuming that the denominator of the elasticity and the ratio of net earnings to gross earnings are measured without error, then the numerator has the same T-statistic as the calculated elasticity. The reported standard error for the elasticity is calculated by dividing the elasticity (0.43) by the 
calculated numerator's T-statistic.

5. Devereux (2004): Table 4, panel 2, column (1), own-wage elasticity. Participation is defined as positive work hours in the past calendar year. Standard error from same table.

6. Eissa and Hoynes (2004): Table 6, elasticity of participation with respect wages, average estimate of married women and married men, 2nd row from bottom. Participation is defined as positive work hours in the last year. Standard errors are calculated by recreating the authors' elasticity calculation as described on page 1951 using estimates from Table 6 and using the delta method. Base participation and wage rates are calculated from Table 2, using weighted averages of the 3rd and 4th columns based on number of observations reported in the bottom row. The reported standard error is created by combining the married women and married men standard errors as above.

7. Liebman and Saez (2006): The numerator for the elasticity is computed as $\log (.483-$ .012) $\log (.483)$ using the Change in Wife Labor Force Participation reported in row (1) and column (2) of Table 6 and the Percent of Wives with Positive Earnings (1990-1992) reported in column (3) of Table 5. The denominator for the elasticity is computed as $\log (1-.419)-\log (1-.31)$ based on the change in tax rates reported on pages 10-11 for OBRA93. Participation is defined as an indicator for positive annual earnings in the past year. Standard error is constructed using the delta method assuming that the change in tax rates is measured without error. This calculation uses the standard error on Change in Wife Labor Force Participation in Table 6 and the Percent of Wives with Positive Earnings as well as the sample size from Table 5.

8. Meghir and Phillips (2010): Page 247, last paragraph, average of single and married men in-work-income elasticities, 0.27 and 0.53 respectively. For the standard errors, the authors' calculations are replicated as described on page 247 using standard errors from Table 3.1, rows (1) and (4), column (4). The standard errors are then calculated using the delta method for each of the estimates, which are then combined to create the reported standard error.

9. Blundell, Bozio and Laroque (2011): Page 38, median overall extensive elasticity. Participation is defined as positive work hours in the past calendar year. Standard error was not reported.

10. Carrington (1996): OLS estimates from Table 2. We approximate the populationconstant employment elasticity as the difference between the employment elasticity in column (1) and the population elasticity in column (5). The standard error is calculated from corresponding standard errors on elasticities under the assumption that the population and employment elasticity estimates are uncorrelated.

11. Gruber and Wise (1999): Using data reported in Table 1, the elasticity estimate is based on a regression of $\log$ (labor force participation at age 59) on $\log$ (effective net-of-tax rate) across countries. Labor force participation is defined as 1 minus fraction of Men Out of Labor Force at age 59; effective net-of-tax rate is defined as 1-implicit tax on earnings. The Netherlands is omitted from the regression because it has an implicit tax above 1. Reported standard error is from the same regression.

12. Bianchi, Gudmundsson, and Zoega (2001): Estimate and standard error from average of the elasticities for men and women reported in the text, paragraph 4, page 1570. Participation is defined at the weekly level (fraction of weeks worked in the past year).

13. Card and Hyslop (2005): From Figure 3, labor force participation before the SSP experiment is $23.6 \%$, and the difference between the treatment and control groups during the SSP eligibility period is $13.5 \%$. Estimated average tax rates are computed from figures in Lin et al. (1998) as described in Appendix A. Participation is defined as any employment 
in the past month. To compute standard errors, sample sizes in Table 2 adjusted for sample attrition as described in footnote 18 were combined with the data on participation rates from Figure 3. The delta method was then used assuming the change in net-of-tax wage rates was measured without error.

14. Brown (2009): We obtain an estimate of 0.08 for the elasticity of retirement age with respect to the wage using the average of the three estimates reported in column 4 of Table 2 . Footnote 33 and Section 6.1 suggest that this is the author's preferred estimate. To convert this retirement age elasticity into an elasticity of years of work with respect to the wage rate, we follow footnote 30 and multiply the elasticity by the ratio of the mean age at retirement to the mean years of service reported in Table 1 . The resulting elasticity is $0.08 \times(60.73 / 26.75)$. Participation is defined as years of work, with variation on the retirement margin. The standard error is constructed from the same table and assumes that the ratio of mean age at retirement to mean years of service, for which a standard error is not reported, is measured without error.

15. Manoli and Weber (2011): Table 5, re-weighted elasticities. We first obtain separate elasticities for men and women by taking a weighted averages of the re-weighted elasticities; the weights are computed based on the fraction of individuals at each tenure threshold. The elasticity for men is 0.12 and the elasticity for women is 0.38 . We then take an unweighted average of these numbers to obtain the overall elasticity of 0.25 . The standard error is constructed from the same table using the same weighted average methodology.

\section{Appendix C. Micro vs. Macro Elasticities (Table 2)}

This appendix describes how each of the values in Table 2 are calculated. With the exception of the Frisch aggregate hours macro elasticity, the aggregate hours elasticities are defined as the sums of the intensive and extensive margin elasticities.

Hicksian, extensive margin: The micro estimate is the mean of the estimates in Panel A of Table 1. The macro estimate is computed by taking the mean of 0.13 from Davis and Henrekson (2005), 0.14 from Nickell (2003), and 0.25 from Prescott (2004). The elasticity from Davis and Henrekson is computed using the log difference in employment based on the slope coefficient in Table 3 (bottom panel, Sample C) and the sample means of labor force participation and tax rates in Table 1 for the corresponding sample. The elasticity from Nickell is computed using the average point estimate of 2 percent (reported on page 8 ) and the sample means of employment rates and tax rates from Tables 1 and 2, respectively. The elasticity from Prescott is calculated by regressing log labor force participation rates from OECD Stat Extracts on log net-of-tax rates using the same sample of countries and years as Prescott. ${ }^{36}$ The data on tax rates is taken from Table 2 of Prescott (2004). The data on labor force participation rates are missing for Canada and the U.K. in the 1970s and these observations are therefore excluded.

Hicksian, intensive margin: The micro estimate is the preferred minimum- $\delta$ estimate using Panels A and B in Table 1 of Chetty (2012). The macro estimate is the mean of the values reported by Davis and Henrekson (2005) and Prescott (2004). The value from Davis and Henrekson (2005) is computed using log differences in annual hours per employed adult based

\footnotetext{
${ }^{36}$ The data are for men and women aged 15-64 for 1970-1974 and 1993-1996 in order to match Prescott's data. Data are available from OECD Stat Extracts at the following URL: http://stats.oecd.org/Index.aspx?DataSetCode=LFS_SEXAGE_I_R
} 
on the slope coefficient in Table 2.3 (middle panel, Sample C) and the sample means of annual hours per employed person and tax rates in Table 2.1 for the corresponding sample. The elasticity estimate can be interpreted as a compensated labor supply elasticity if government expenditure is viewed as unearned income in the aggregate. The value from Prescott (2004) is calculated by regressing log hours per worker on log net-of-tax rates using OECD data reported by Prescott in Table 2 on hours per adult, which are converted to hours per worker using labor force participation rates from the OECD Stat Extracts described above. The data on labor force participation rates are missing for Canada and the U.K. in the 1970s and these observations are therefore excluded. The elasticity estimate can be interpreted as a compensated labor supply elasticity if government expenditure is viewed as unearned income in the aggregate.

Frisch, intensive margin elasticities: the micro estimate is the unweighted mean of 0.70 in Table 2 from Pistaferri (2003) and 0.37 from Bianchi et al. (2001), as reported in Chetty (2012). The macro value in brackets is set equal to the micro estimate.

Frisch, extensive margin: The micro estimate is the mean of the estimates in Panel B of Table 1. The macro value in brackets is computed by subtracting the Frisch micro intensive margin elasticity from the Frisch aggregate hours macro elasticity.

Frisch, aggregate hours macro: the estimate is computed by taking the mean of the aggregate (total hours) elasticities implied by two models of business cycles: (1) Cho and Cooley (1994): 2.61 from the sum of the intensive and extensive margin elasticities implied by the parameters in Table 2 and (2) King and Rebelo (1999): 4 for representative agent RBC models, from page 975 .

\section{Technical Appendix}

This technical appendix describes how we simulate the Rogerson and Wallenius model. We solve the model analytically as in RW (2007), the working paper version of RW (2009). All of our extensions follow RW's solution method (with slightly modified notation). Our results have been verified with iterative methods. The code for our simulations is available at http://obs.rc.fas.harvard.edu/chetty/index.html

Standard Rogerson and Wallenius Model. As described in the main text, each generation solves

$$
\max _{c, h(a)} \log (c)-\alpha \int_{0}^{1} \frac{h(a)^{1+\gamma}}{1+\gamma} d a \text { s.t. } c=(1-\tau) \int_{0}^{1} e(a) \max \{h(a)-\bar{h}, 0\} d a+T
$$

where $e(a)=1-2\left(1-e_{1}\right)\left|\frac{1}{2}-a\right|$ is a tent-shaped life-cycle productivity profile as shown in Figure 1. Similar to RW, we assume that the one unit of time corresponds to 60 years. We assume that time $t=0$ corresponds to age 16, while time $t=1$ corresponds to age 76 . The model can be solved iteratively by backwards induction, but given RW's choice of functional forms it can be solved analytically as well. For consistency with RW (2007), we work with generic functions for the utility of consumption $(u(c))$, the disutility of labor supply $(v(h))$, and efficiency units of labor per hour worked ( $\operatorname{so} g(h)=\max \{h-\bar{h}, 0\}$ above) and plug in specific functional forms at the end. Each generation solves

$$
\max _{c(a), h(a)} \int_{0}^{1} u(c)-v(h(a)) d a \text { s.t. } c=(1-\tau) \int_{0}^{1} e(a) g(h(a)) d a+T
$$


RW show that the optimal solution has two properties. First, there exists a cutoff $e^{*}$ such that $h^{*}(a)>0$ if $e(a)>e^{*}$ and $h^{*}(a)=0$ if $e(a) \leq e^{*}$. Consequently, if $e(a)$ is tent shaped, there will be a date at which the individual enters the labor force and a date at which they exit, and if $e(a)$ is symmetric these dates will be symmetric around $a=.5$. Second, if $h^{*}(a)$ is optimal and $h^{*}\left(a_{1}\right)>0$ and $h^{*}\left(a_{2}\right)>0$ then $e\left(a_{1}\right)>e\left(a_{2}\right) \Rightarrow h^{*}\left(a_{1}\right) \geq h^{*}\left(a_{2}\right)$ so that the individual works weakly more hours when they have higher productivity. Finally, note that hourly wages are $w^{h}(a)=e(a) g(h(a)) / h(a)$.

Because individuals have a discrete labor market entry and retirement date, an individual works at all times on some interval $\left[A^{E}, A^{R}\right]$ where $A^{E}$ is the labor market entry date and $A^{R}$ is the retirement date. The problem can thus be rewritten:

$$
\max _{c, h(a), A^{E}, A^{R}} u(c)-\int_{A^{E}}^{A^{R}} v(h(a)) d a \text { s.t. } c=(1-\tau) \int_{A^{E}}^{A^{R}} e(a) g(h(a)) d a+T
$$

In order to solve the model, RW re-order time, so that the most productive moment is at time 0 and the least productive moment is at time 1 . Formally, define $\tilde{e}(\lambda)$ for $\lambda \in[0,1]$ so that for each $\lambda, \tilde{e}(\lambda)$ solves

$$
\lambda=\int_{0}^{1} I\{e(a) \geq \tilde{e}(\lambda)\} d a
$$

Then $\tilde{e}(\lambda)$ is the productivity level such that the individual has a productivity greater than $\tilde{e}(\lambda)$ for $\lambda$ of their life and is strictly decreasing by construction. The maximization problem can then be written as

$$
\max _{c, h(\lambda), \lambda^{*}} u(c)-\int_{0}^{\lambda^{*}} v(h(a)) d \lambda \text { s.t. } c=(1-\tau) \int_{0}^{\lambda^{*}} \tilde{e}(\lambda) g(h(\lambda)) d \lambda+T
$$

because it will be assumed that $e(a)$ is symmetric around .5 , if $\lambda^{*}<1, A^{E}=.5-\frac{\lambda^{*}}{2}$ and $A^{R}=.5+\frac{\lambda^{*}}{2}$.

Under the parameters chosen by RW and that we use in our simulations, the constraint $h(a)<1$ is always slack and can therefore be ignored. This permits an analytical solution to the problem. Plugging in the budget constraint and differentiating with respect to $\lambda^{*}$ and $h(\lambda)$ leads to two first order conditions:

$$
\begin{aligned}
& \frac{v\left(h\left(\lambda^{*}\right)\right)}{u^{\prime}\left((1-\tau) \int_{0}^{\lambda^{*}} \tilde{e}(\lambda) g(h(\lambda)) d \lambda+T\right)}=(1-\tau) \tilde{e}\left(\lambda^{*}\right) g\left(h\left(\lambda^{*}\right)\right) \\
& \frac{v^{\prime}(h(\lambda))}{u^{\prime}\left((1-\tau) \int_{0}^{\lambda^{*}} \tilde{e}(\lambda) g(h(\lambda)) d \lambda+T\right)}=(1-\tau) \tilde{e}(\lambda) g^{\prime}(h(\lambda))
\end{aligned}
$$

A balanced budget for the government implies that:

$$
\tau \int_{0}^{\lambda^{*}} \tilde{e}(\lambda) g(h(\lambda)) d \lambda=T
$$


so the two FOCs can be rewritten as:

$$
\begin{aligned}
& \frac{v\left(h\left(\lambda^{*}\right)\right)}{u^{\prime}\left(\int_{0}^{\lambda^{*}} \tilde{e}(\lambda) g(h(\lambda)) d \lambda\right)}=(1-\tau) \tilde{e}\left(\lambda^{*}\right) g\left(h\left(\lambda^{*}\right)\right) \\
& \frac{v^{\prime}(h(\lambda))}{u^{\prime}\left(\int_{0}^{\lambda^{*}} \tilde{e}(\lambda) g(h(\lambda)) d \lambda\right)}=(1-\tau) \tilde{e}(\lambda) g^{\prime}(h(\lambda))
\end{aligned}
$$

Note that if the individual works their whole life, $\lambda^{*}=1$ and only the second FOC will hold. Additionally, the second $(h(\lambda))$ FOC implies that

$$
\frac{v^{\prime}(h(\lambda))}{(1-\tau) \tilde{e}(\lambda) g^{\prime}(h(\lambda))}=u^{\prime}\left(\int_{0}^{\lambda^{*}} \tilde{e}(\lambda) g(h(\lambda)) d \lambda\right)=\text { constant } \forall \lambda \in\left[0, \lambda^{*}\right]
$$

This differential equation pins down the entire hours profile once $h(0)=h^{\text {max }}$ is known. Since $\lambda^{*}$ fully pins down $A^{E}$ and $A^{R}$, the optimum is defined by two free variables, $h^{\text {max }}$ and $\lambda^{*}$, pinned down by the two FOCs. If $\lambda^{*}=1$ due to a corner solution, the second FOC will pin down $h^{\text {max }}$, the only free variable.

The two FOCs can be manipulated to simplify the equilibrium conditions for $h^{\mathrm{max}}$ and $\lambda^{*}$. First, divide the two FOCs to eliminate the integral and evaluate at $\lambda=0$ to get:

$$
\frac{v\left(h\left(\lambda^{*}\right)\right)}{\tilde{e}\left(\lambda^{*}\right) g\left(h\left(\lambda^{*}\right)\right)}=\frac{v^{\prime}\left(h^{\max }\right)}{e^{\max } g^{\prime}\left(h^{\max }\right)}
$$

RW show that this defines an increasing relationship between $h^{\max }$ and $\lambda^{*}$. Second, evaluate the second FOC at $\lambda=0$ to get:

$$
\frac{(1-\tau) e^{\max } g^{\prime}\left(h^{\max }\right)}{v^{\prime}\left(h^{\max }\right)}=\frac{1}{u^{\prime}\left(\int_{0}^{\lambda^{*}} \tilde{e}(\lambda) g(h(\lambda)) d \lambda\right)}
$$

RW show that this defines a decreasing relationship between $h^{\max }$ and $\lambda$. (5) and (6) thus together define a unique equilibrium that can be solved numerically given $e_{0}, e_{1}, \alpha$, $\bar{h}$, and $\gamma$. Figure 1 illustrates the hours profile (solid green line) generated by the numerical solution using parameter values from the EITC simulation presented in the main text alongside the productivity profile (dashed blue line). 


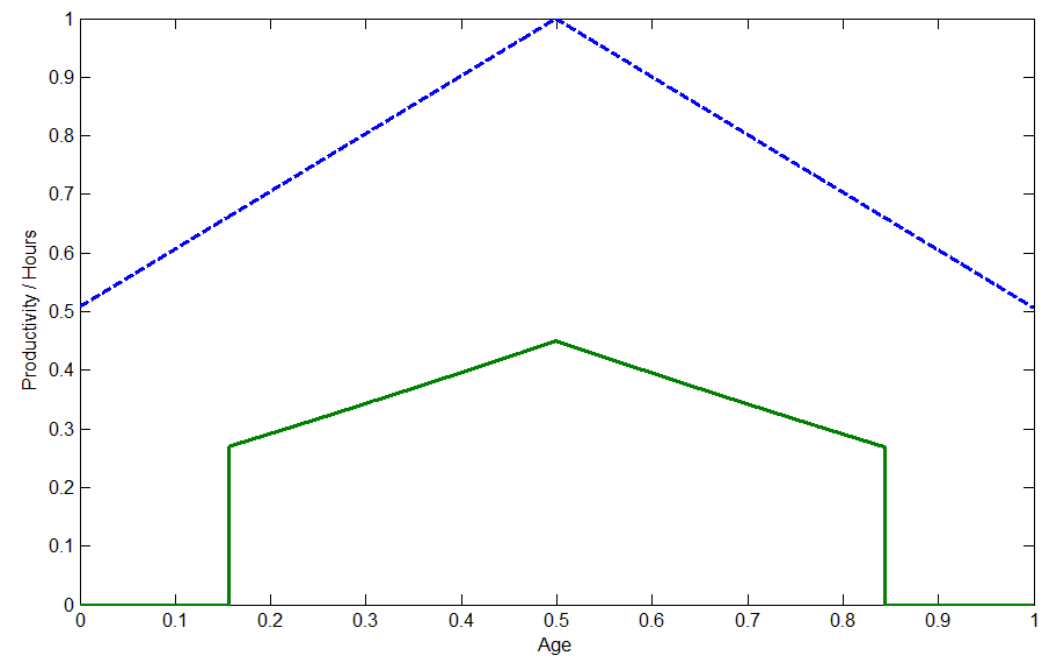

Appendix Figure 1: Productivity and Hours Profiles in the RW Model

We now plug in the functional forms $u(c)=\ln (c), v(h)=\alpha \frac{h^{1+\gamma}}{1+\gamma}, g(h)=h-\bar{h}$, and to choose a functional form for $\tilde{e}(\lambda)$. RW assume a linear formulation for the productivity profile in $\lambda$ time:

$$
\tilde{e}(\lambda)=\tilde{e}(\lambda)=e_{0}-\left(e_{0}-e_{1}\right) \lambda=(1-\lambda) e_{0}+\lambda e_{1}
$$

Normalizing $e_{0}=1$, this implies the an age-productivity profile of $e(a)=1-2\left(1-e_{1}\right)\left|\frac{1}{2}-a\right|$. With these functional forms, (5) and (6) simplify to:

$$
\begin{aligned}
\frac{\alpha\left(h^{\max }\right)^{\gamma}}{e_{0}} & =\frac{\alpha h\left(\lambda^{*}\right)^{1+\gamma}}{(1+\gamma)\left(\left(1-\lambda^{*}\right) e_{0}+\lambda^{*} e_{1}\right)\left(h\left(\lambda^{*}\right)-\bar{h}\right)} \\
\frac{(1-\tau) e_{0}}{\alpha\left(h^{\max }\right)^{\gamma}} & =\int_{0}^{\lambda^{*}}\left((1-\lambda) e_{0}+\lambda e_{1}\right)(h(\lambda)-\bar{h}) d \lambda
\end{aligned}
$$

The differential equation for hours can be manipulated to obtain

$$
h(\lambda)=h^{\max }\left(\frac{(1-\lambda) e_{0}+\lambda e_{1}}{e_{0}}\right)^{\frac{1}{\gamma}}
$$

Plugging this into the two FOCs and simplifying gives

$$
\begin{aligned}
\bar{h} & =\frac{\gamma}{1+\gamma} h^{\max }\left(\frac{\left(1-\lambda^{*}\right) e_{0}+\lambda^{*} e_{1}}{e_{0}}\right)^{\frac{1}{\gamma}} \\
\alpha= & \frac{e_{0}(1-\tau)}{\left(h^{\max }\right)^{\gamma}\left\{h^{\max } \frac{\left[\left(1-\lambda^{*}\right) e_{0}+\lambda^{*} e_{1}\right]^{\frac{1}{\gamma}+2}-\gamma e_{0}^{\frac{1}{\gamma}+2}}{e_{0}^{\frac{1}{\gamma}}\left(\frac{1}{\gamma}+2\right)\left(e_{1}-e_{0}\right)}-\bar{h}\left[\frac{\left(\left(1-\lambda^{*}\right) e_{0}+\lambda^{*} e_{1}\right)^{2}-e_{0}^{2}}{2\left(e_{1}-e_{0}\right)}\right]\right\}}
\end{aligned}
$$

The intensive margin Frisch elasticity, which is one of the moments we use for calibration, can be calculated analytically. Rearranging equation (6) and plugging in the functional forms and 
normalizing $e_{0}=1$ gives:

$$
(1-\tau) u^{\prime}(c)=\alpha\left(h^{\max }\right)^{\gamma}
$$

Taking logs and differentiating with respect to $1-\tau$ holding $u^{\prime}(c)$ constant gives:

$$
\varepsilon_{h^{\max }, 1-\tau}^{\text {Frisch }}=\frac{1}{\gamma}
$$

Because the hours profile shifts vertically by $h^{\max }$ when taxes change, this is also the intensive margin Frisch elasticity in the model. Consequently, we can calibrate the model to a particular intensive margin Frisch elasticity $\varepsilon_{\mathrm{INT}}$ by choosing $\gamma=\frac{1}{\varepsilon_{\mathrm{INT}}}$.

The model is calibrated as described in Appendix A. With $\left\{\alpha, e_{1}, \bar{h}, \gamma\right\}$ chosen, the model can be solved numerically by inverting equations (9) and (10) to solve for $h^{\text {max }}$ and $\lambda^{*}$.

Asset Profile in the RW Model. In order to characterize the impact of unanticipated tax changes on labor supply, we need to know assets at the time of the tax change. Because assets and age are the only state variables, assets holdings are the time of the tax change are adequate to solve the model.

We assume that each generation receives a lump-sum rebate equal to the taxes they pay at each instant in time. Under this assumption, it is straightforward to back out an agent's asset position at any time. Note that the labor market entry and retirement dates are $A^{E}=.5-\frac{\lambda^{*}}{2}$ and $A^{R}=.5+\frac{\lambda^{*}}{2}$, respectively. Between $A^{E}$ and $A^{R}$, hours are

$$
h(a)=h^{\max }\left(\frac{e(a)}{e_{0}}\right)^{\frac{1}{\gamma}}=h^{\max }\left(\frac{e_{0}-2\left(e_{0}-e_{1}\right)|.5-a|}{e_{0}}\right)^{\frac{1}{\gamma}}
$$

and so earnings when working are

$$
\begin{aligned}
w(a) & =g(h(a)) e(a) \\
& =\left[h^{\max }\left(\frac{e_{0}-2\left(e_{0}-e_{1}\right)|.5-a|}{e_{0}}\right)^{\frac{1}{\gamma}}-\bar{h}\right]\left(e_{0}-2\left(e_{0}-e_{1}\right)|.5-a|\right)
\end{aligned}
$$

while consumption is always

$$
c=h^{\max } \frac{\left[e_{0}-\lambda^{*}\left(e_{0}-e_{1}\right)\right]^{\frac{1}{\gamma}+2}-\gamma e_{0}^{\frac{1}{\gamma}+2}}{e_{0}^{\frac{1}{\gamma}}\left(\frac{1}{\gamma}+2\right)\left(e_{1}-e_{0}\right)}-\bar{h} e_{0} \lambda^{*}+\bar{h}\left(e_{0}-e_{1}\right) \frac{\left(\lambda^{*}\right)^{2}}{2} .
$$

Thus assets at time $t$ are:

$$
S_{t}=\left\{\begin{array}{c}
-c a, a<A^{E} \\
-c a+\int_{A^{E}}^{a}\left[h^{\max }\left(\frac{e_{0}-2\left(e_{0}-e_{1}\right)|.5-a|}{e_{0}}\right)^{\frac{1}{\gamma}}-\bar{h}\right]\left(e_{0}-2\left(e_{0}-e_{1}\right)|.5-a|\right) d a, a \in\left[A^{E}, A^{R}\right] \\
-c a+c, a>A^{R}
\end{array}\right.
$$


The middle term can be simplified analytically to:

$$
\begin{aligned}
S_{t}= & -c a+h^{\max } \frac{\left(e_{1}+2 a\left(e_{0}-e_{1}\right)\right)^{\frac{1}{\gamma}+2}-\left(e_{1}+2 A^{E}\left(e_{0}-e_{1}\right)\right)^{\frac{1}{\gamma}+2}}{2 e_{0}^{\frac{1}{\gamma}}\left(\frac{1}{\gamma}+2\right)\left(e_{0}-e_{1}\right)} \\
& -\bar{h} e_{1}\left(a-A_{1}\right)-\bar{h}\left(a^{2}-\left(A^{E}\right)^{2}\right)\left(e_{0}-e_{1}\right)
\end{aligned}
$$

if $a \leq .5$ and

$$
\begin{aligned}
S_{t}= & -c a+S_{.5}+h^{\max } \frac{\left(2 e_{0}-e_{1}-2 a\left(e_{0}-e_{1}\right)\right)^{\frac{1}{\gamma}+2}-\left(e_{0}\right)^{\frac{1}{\gamma}+2}}{2\left(2+\frac{1}{\gamma}\right)\left(e_{1}-e_{0}\right)} \\
& -\bar{h}\left(2 e_{0}-e_{1}\right)(a-.5)+\bar{h}\left(a^{2}-.5\right)\left(e_{0}-e_{1}\right)
\end{aligned}
$$

if $a \geq .5$, where

$$
\begin{aligned}
S_{.5}= & h^{\max } \frac{\left(e_{1}+\left(e_{0}-e_{1}\right)\right)^{\frac{1}{\gamma}+2}-\left(e_{1}+2 A^{E}\left(e_{0}-e_{1}\right)\right)^{\frac{1}{\gamma}+2}}{2 e_{0}^{\frac{1}{\gamma}}\left(\frac{1}{\gamma}+2\right)\left(e_{0}-e_{1}\right)} \\
& -\bar{h} e_{1}\left(.5-A^{E}\right)-\bar{h}\left(.5^{2}-\left(A^{E}\right)^{2}\right)\left(e_{0}-e_{1}\right)
\end{aligned}
$$

We solve each generation's problem separately and then add across generations, which are weighted equally, to simulate the overall response to our quasi-experiments.

Permanent Tax Changes. We first consider the EITC simulation of a one time permanent tax change. Consider the problem of an age $\underline{t}$ individual with assets $S_{\underline{t}}$ as calculated in the previous section who faces a new tax schedule $\tau$. The individual smooths consumption across periods and solves

$$
\max _{c, h(a)}(1-\underline{t}) u(c)-\int_{\underline{t}}^{1} v(h(a)) d a \text { s.t. }(1-\underline{t}) c=(1-\tau) \int_{\underline{t}}^{1} e(a) g(h(a)) d a+T+S_{\underline{t}}
$$

This equation can be solved by analytically re-ordering time as described above in the solution to the RW model. All the solution requires is changing the $\tilde{e}(\lambda)$ profile, with $\lambda \in[0,1-\underline{t}]$, to reflect the fact that some time has already elapsed.

The new $\tilde{e}(\lambda)$ function will be piecewise linear, as illustrated in Figure 2 using the parameter values used for the EITC simulation in the main text. When $\underline{t}=0, e(\lambda)=e_{0}-\lambda\left(e_{0}-e_{1}\right)$ as above, illustrated by the solid blue line in Figure 2 below. As $\underline{t}$ rises, $e(\lambda)$ will be piecewise linear, as the low productivity time periods up to $\underline{t}$ will occur once, not twice. Thus $e(\lambda)$ will look the same for low $\lambda$, but after $2 \underline{t}$ it will have twice the slope, as shown by the green dotted line in Figure 2. When $\underline{t}$ hits .5, no productivity level occurs twice and so the function will have twice the slope and be linear again. However $e^{\max }$ will fall to $e_{0}-2\left(e_{0}-e_{1}\right)(\underline{t}-.5)$. This case is illustrated by the red dash-dot line in Figure 2. 


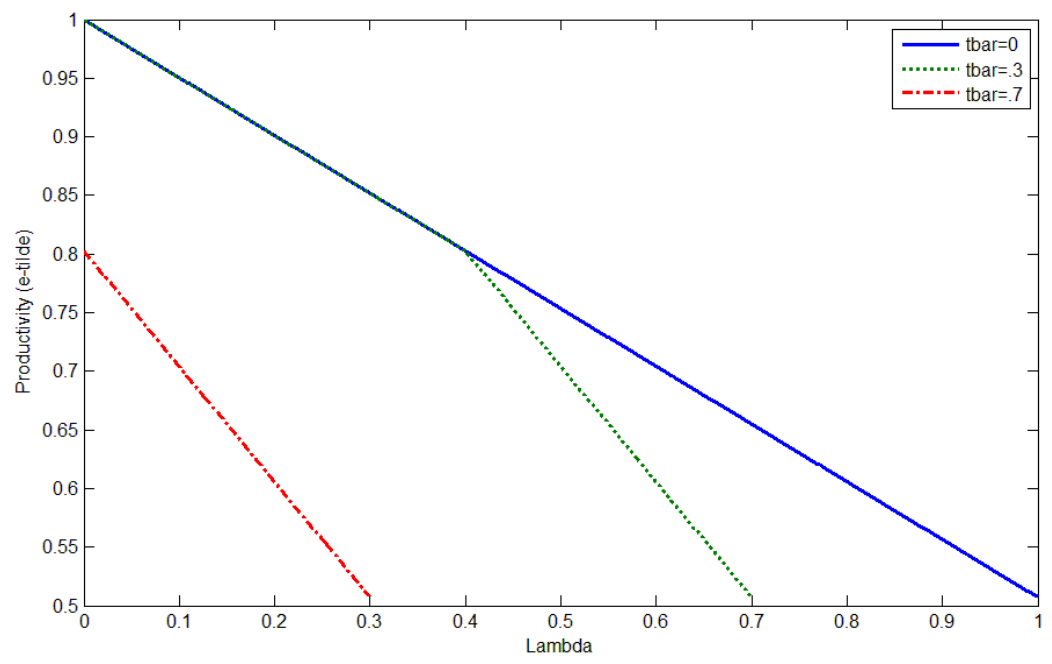

Appendix Figure 2: Productivity Profile $\widetilde{e}(\lambda)$ For Various Values of Time of Tax Change $\bar{t}$

Consequently, if $\underline{t}<.5, \tilde{e}(\lambda)$ is

$$
\tilde{e}(\lambda)=\left\{\begin{array}{c}
e_{0}-\lambda\left(e_{0}-e_{1}\right) \text { if } \lambda \leq 1-2 \underline{t} \\
2 e_{0}-e_{1}-2(\underline{t}+\lambda)\left(e_{0}-e_{1}\right) \text { if } \lambda>1-2 \underline{t}
\end{array}\right.
$$

If $\underline{t}>.5, \tilde{e}(\lambda)$ is

$$
\tilde{e}(\lambda)=2 e_{0}-e_{1}-2(\underline{t}+\lambda)\left(e_{0}-e_{1}\right)
$$

With this new $\tilde{e}(\lambda)$ profile, the problem becomes

$$
\max _{\lambda^{*} \in[0,1-\underline{t}], h(\lambda)}(1-\underline{t}) u\left(\frac{(1-\tau) \int_{0}^{\lambda^{*}} \tilde{e}(\lambda) g(h(\lambda)) d \lambda+T+S_{\underline{t}}}{1-\underline{t}}\right)-\int_{0}^{\lambda^{*}} v(h(\lambda)) d a
$$

The model will have an interior solution if the tax change is not large enough to induce $h>1$. We show this is not the case in our three applications by reporting maximum and minimum hours after the tax change for each simulation in appendix A. With this constraint slack, the model can be solved analytically. Taking the first order conditions, plugging in the government's balanced budget constraint, $T=\int_{0}^{\lambda^{*}} \tilde{e}(\lambda) g(h(\lambda)) d \lambda$, and simplifying gives:

$$
\begin{aligned}
& \frac{v\left(h\left(\lambda^{*}\right)\right)}{u^{\prime}(c)}=(1-\tau) \tilde{e}\left(\lambda^{*}\right) g\left(h\left(\lambda^{*}\right)\right) \\
& \frac{v^{\prime}(h(\lambda))}{u^{\prime}(c)}=(1-\tau) \tilde{e}(\lambda) g^{\prime}(h(\lambda))
\end{aligned}
$$

As in the basic RW model, the second FOC implies

$$
\frac{v^{\prime}(h(\lambda))}{(1-\tau) \tilde{e}(\lambda) g^{\prime}(h(\lambda))}=u^{\prime}(c)=\text { constant } \forall \lambda \in\left[0, \lambda^{*}\right]
$$

which pins down the hours profile.

The two FOCs can be simplified by dividing the two FOCs to eliminate the integral and 
evaluating at $\lambda=0$ and by evaluating the second FOC at $\lambda=0$. With our functional forms, this yields:

$$
\begin{aligned}
\frac{\alpha h\left(\lambda^{*}\right)^{1+\gamma}}{(1+\gamma)\left(h\left(\lambda^{*}\right)-\bar{h}\right) \tilde{e}\left(\lambda^{*}\right)} & =\frac{\alpha\left(h^{\max }\right)^{\gamma}}{e^{\max }} \\
\frac{(1-\tau) e^{\max }(1-\underline{t})}{\alpha\left(h^{\max }\right)^{\gamma}} & =\int_{0}^{\lambda^{*}} \tilde{e}(\lambda)(h(\lambda)-\bar{h}) d \lambda+S_{\underline{t}}
\end{aligned}
$$

Finally, we know that $h(\lambda)=h^{\max }\left(\frac{\tilde{e}(\lambda)}{e^{\max }}\right)^{\frac{1}{\gamma}}$ from the differential equation for the hours profile. The two FOC simplify to:

$$
\begin{aligned}
\lambda^{*} & =\tilde{e}^{-1}\left(e^{\max }\left(\frac{\bar{h}}{h^{\max }} \frac{1+\gamma}{\gamma}\right)^{\gamma}\right) \\
\frac{(1-\tau) e^{\max }(1-\underline{t})}{\alpha\left(h^{\max }\right)^{\gamma}} & =\frac{h^{\max }}{\left(e^{\max }\right)^{\frac{1}{\gamma}}} \int_{0}^{\lambda^{*}} \tilde{e}(\lambda)^{1+\frac{1}{\gamma}} d \lambda-\bar{h} \int_{0}^{\lambda^{*}} \tilde{e}(\lambda) d \lambda+S_{\underline{\underline{t}}}
\end{aligned}
$$

which we solve numerically.

With the optimal $h^{\max }$ and $\lambda^{*}$ in hand, it is easy to build the hours profile in calendar time. If $\lambda^{*}<1-2 \underline{t}$, the working life will be entirely after $\underline{t}$. The individual will enter the labor force at date $\overline{A^{E}}=.5-\frac{\lambda^{*}}{2}$ and exit at date $A^{R}=.5+\frac{\bar{\lambda}^{*}}{2}$. If $\lambda^{*}>1-2 \underline{t}$, the agent will have already started working so $A^{E}=\underline{t}$. They will thus exit at date $A^{R}=\underline{t}+\lambda^{*}$. To build the hours profile, we build a function $\lambda(a)$ : if $\underline{t}>.5$,

$$
\lambda(a)=a-\underline{t}
$$

and if $\underline{t}<.5$,

$$
\lambda(a)=\left\{\begin{array}{c}
2|a-.5| \text { if }|a-.5|<\underline{t} \\
a-\underline{t} \text { otherwise }
\end{array}\right.
$$

The hours profile is then generated by noting that:

$$
h(a)=\left\{\begin{array}{c}
h^{\max }\left(\frac{\tilde{e}(\lambda(a))}{e^{\max }}\right)^{\frac{1}{\gamma}}, a \in\left[A^{E}, A^{R}\right] \\
0 \text { otherwise }
\end{array}\right.
$$

Temporary Tax Changes. The solution method for Iceland and the Canada simulations both of which feature a temporary tax reduction — is similar to the EITC solution. However, now there are two different periods in which the above problem is solved - one with tax $\tau_{0}$ and one with tax $\tau_{1}$ - and thus the solution consists of a system of four equations and four unknowns $-h^{\max }$ and $\lambda^{*}$ in each tax regime.

Consider the problem of an age $\underline{t}$ individual with assets $S_{\underline{t}}$. From $\underline{t}$ to $\bar{t}$ they face a tax rate $\tau_{0}$, and then the tax rate changes to $\tau_{1}$. In this section, we assume that $\bar{t}<1$, as if $\bar{t} \geq 1$ the individual only faces $\tau_{0}$ the rest of their life and the problem reduces to the EITC problem 
described above. With perfect consumption smoothing, the individual's problem is:

$$
\begin{gathered}
\max _{c, h(a)}(1-\underline{t}) u(c)-\int_{\underline{t}}^{1} v(h(a)) d a \\
\text { s.t. }(1-\underline{t}) c=\left(1-\tau_{0}\right) \int_{\underline{t}}^{\bar{t}} e(a) g(h(a)) d a+\left(1-\tau_{1}\right) \int_{\bar{t}}^{1} e(a) g(h(a)) d a+T+S_{\underline{t}}
\end{gathered}
$$

Again re-order time as in RW. There will now be two $\tilde{e}(\lambda)$ functions: $\tilde{e}_{0}\left(\lambda_{0}\right)$ with $\lambda_{0} \in[0, \bar{t}-\underline{t}]$ in the period with taxes $\tau_{0}$ and $\tilde{e}_{1}\left(\lambda_{1}\right)$ with $\lambda_{1} \in[0,1-\bar{t}]$ in the period with taxes $\tau_{1}$. $\tilde{e}_{1}\left(\lambda_{1}\right)$ will look exactly as in the EITC simulation, with $\bar{t}$ replacing $\underline{t}$ : if $\bar{t}<.5$,

$$
\tilde{e}_{1}\left(\lambda_{1}\right)=\left\{\begin{array}{c}
e_{0}-\lambda_{1}\left(e_{0}-e_{1}\right) \text { if } \lambda_{1} \leq 1-2 \bar{t} \\
2 e_{0}-e_{1}-2\left(\bar{t}+\lambda_{1}\right)\left(e_{0}-e_{1}\right) \text { if } \lambda_{1}>1-2 \bar{t}
\end{array}\right.
$$

and if $\bar{t} \geq .5$,

$$
\tilde{e}_{1}\left(\lambda_{1}\right)=2 e_{0}-e_{1}-2\left(\bar{t}+\lambda_{1}\right)\left(e_{0}-e_{1}\right)
$$

As for $\tilde{e}_{0}\left(\lambda_{0}\right)$, if $\bar{t} \leq .5$, then the area between $\underline{t}$ and $\bar{t}$ will only have the increasing side of the absolute value function:

$$
\tilde{e}_{0}\left(\lambda_{0}\right)=e_{0}-\left(1-2 \bar{t}+2 \lambda_{0}\right)\left(e_{0}-e_{1}\right)
$$

Similarly, if $\underline{t} \geq .5$, the the area between $\underline{t}$ and $\bar{t}$ will only have the decreasing side of the absolute value function:

$$
\tilde{e}_{0}\left(\lambda_{0}\right)=2 e_{0}-e_{1}-2\left(e_{0}-e_{1}\right)\left(\underline{t}+\lambda_{0}\right)
$$

If $\underline{t}<.5$ and $\bar{t}>.5$, then we will have part of the absolute value function in the $\tilde{e}_{0}$. Let $t=\min \{\bar{t}-.5, .5-\underline{t}\}$. Then

$$
\tilde{e}_{0}\left(\lambda_{0}\right)=\left\{\begin{array}{c}
e_{0}-\lambda_{0}\left(e_{0}-e_{1}\right) \text { if } \lambda_{0} \leq 2 t \\
e_{0}+2 t\left(e_{0}-e_{1}\right)-2 \lambda_{0}\left(e_{0}-e_{1}\right) \text { if } \lambda_{0}>2 t
\end{array}\right.
$$

With these profiles in hand, we note that under each tax regime an individual will always work if their productivity is above a cutoff level, as in RW. The problem can then be written as:

$$
\max _{\lambda_{0}^{*} \in[0, \bar{t}-\underline{t}], \lambda_{1}^{*} \in[0,1-\bar{t}], h_{0}(\lambda), h_{1}(\lambda)}(1-\underline{t}) u(c)-\int_{0}^{\lambda_{0}^{*}} v\left(h_{0}\left(\lambda_{0}\right)\right) d \lambda_{0}-\int_{0}^{\lambda_{1}^{*}} v\left(h_{1}\left(\lambda_{1}\right)\right) d \lambda_{1}
$$

In this case, the model may not have an interior solution as an agent may find it optimal to work all of the time for which the tax is $\tau_{0}$. We describe how we handle these corner solutions below.

Calculating the FOC's and plugging in the government balanced budget constraint in each 
period gives:

$$
\begin{aligned}
& \frac{v\left(h_{0}\left(\lambda_{0}^{*}\right)\right)}{u^{\prime}(c)}=\left(1-\tau_{0}\right) \tilde{e}_{0}\left(\lambda_{0}^{*}\right) g\left(h_{0}\left(\lambda_{0}^{*}\right)\right) \\
& \frac{v^{\prime}\left(h_{0}\left(\lambda_{0}\right)\right)}{u^{\prime}(c)}=\left(1-\tau_{0}\right) \tilde{e}_{0}\left(\lambda_{0}\right) g^{\prime}\left(h_{0}\left(\lambda_{0}\right)\right) \\
& \frac{v\left(h_{1}\left(\lambda_{1}^{*}\right)\right)}{u^{\prime}(c)}=\left(1-\tau_{1}\right) \tilde{e}_{1}\left(\lambda_{1}^{*}\right) g\left(h_{1}\left(\lambda_{1}^{*}\right)\right) \\
& \frac{v^{\prime}\left(h_{1}\left(\lambda_{1}\right)\right)}{u^{\prime}(c)}=\left(1-\tau_{1}\right) \tilde{e}_{1}\left(\lambda_{1}\right) g^{\prime}\left(h_{1}\left(\lambda_{1}\right)\right)
\end{aligned}
$$

The second FOC implies that:

$$
\begin{aligned}
\frac{v^{\prime}\left(h_{0}\left(\lambda_{0}\right)\right)}{(1-\tau) \tilde{e}\left(\lambda_{0}\right) g^{\prime}\left(h_{0}\left(\lambda_{0}\right)\right)} & =u^{\prime}(c) \\
& =\text { constant } \forall \lambda \in\left[0, \lambda_{0}^{*}\right]
\end{aligned}
$$

As before once we know $h_{0}(0)=h_{0}^{\max }$ all of $h_{0}\left(\lambda_{0}\right)$ is pinned down. Similarly, the fourth FOC implies that:

$$
\frac{v^{\prime}\left(h_{1}\left(\lambda_{1}\right)\right)}{(1-\tau) \tilde{e}\left(\lambda_{1}\right) g^{\prime}\left(h_{1}\left(\lambda_{1}\right)\right)}=u^{\prime}(c)=\text { constant } \forall \lambda \in\left[0, \lambda_{1}^{*}\right]
$$

We can then follow the same steps as above, dividing the two FOCs and evaluating at $\lambda_{0}=0$ and $\lambda_{1}=0$ and evaluating the second and fourth FOCs at $\lambda_{0}=0$ and $\lambda_{1}=0$, respectively. Plugging in the functional forms one gets four equilibrium conditions:

$$
\begin{aligned}
& h_{0}^{\max }=\bar{h} \frac{1+\gamma}{\gamma}\left(\frac{e_{0}^{\max }}{\tilde{e}_{0}\left(\lambda_{0}^{*}\right)}\right)^{\frac{1}{\gamma}} \\
& h_{1}^{\max }=\bar{h} \frac{1+\gamma}{\gamma}\left(\frac{e_{1}^{\max }}{\tilde{e}_{1}\left(\lambda_{1}^{*}\right)}\right)^{\frac{1}{\gamma}} \\
& \frac{\left(1-\tau_{0}\right) e_{0}^{\max }(1-\underline{t})}{\alpha\left(h_{0}^{\max }\right)^{\gamma}}=\frac{h_{0}^{\max }}{\left(e_{0}^{\max }\right)^{\frac{1}{\gamma}}} \int_{0}^{\lambda_{0}^{*}} \tilde{e}_{0}\left(\lambda_{0}\right)^{1+\frac{1}{\gamma}} d \lambda_{0}-\bar{h} \int_{0}^{\lambda_{0}^{*}} \tilde{e}\left(\lambda_{0}\right) d \lambda_{0}+ \\
& \frac{h_{1}^{\max }}{\left(1-\tau_{1}\right) e_{1}^{\max }(1-\underline{t})} \int_{1}^{\lambda_{1}^{*}} \tilde{e}_{1}\left(\lambda_{1}\right)^{1+\frac{1}{\gamma}} d \lambda_{1}-\bar{h} \int_{0}^{\lambda_{1}^{*}} \tilde{e}\left(\lambda_{1}\right) d \lambda_{1}+S_{\underline{t}} \frac{h_{0}^{\max }}{\left(h_{1}^{\max }\right)^{\frac{1}{\gamma}}} \int_{0}^{\lambda_{0}^{*}} \tilde{e}_{0}\left(\lambda_{0}\right)^{1+\frac{1}{\gamma}} d \lambda_{0}-\bar{h} \int_{0}^{\lambda_{0}^{*}} \tilde{e}\left(\lambda_{0}\right) d \lambda_{0}+ \\
& \frac{h_{1}^{\max }}{\left(e_{1}^{\max }\right)^{\frac{1}{\gamma}}} \int_{0}^{\lambda_{1}^{*}} \tilde{e}_{1}\left(\lambda_{1}\right)^{1+\frac{1}{\gamma}} d \lambda_{1}-\bar{h} \int_{0}^{\lambda_{1}^{*}} \tilde{e}\left(\lambda_{1}\right) d \lambda_{1}+S_{\underline{t}}
\end{aligned}
$$

These four equations hold for interior solutions: $\lambda_{0}^{*} \in(0, \bar{t}-\underline{t})$ and $\lambda_{1}^{*} \in(0,1-\bar{t})$. They also work at the $\lambda_{0}^{*}=0$ and $\lambda_{1}^{*}=0$ corner solutions because then the hours problem is trivial. At the $\lambda_{0}^{*}=\bar{t}-\underline{t}$ corner solution, $\lambda_{1}^{*}, h_{0}^{\max }$, and $h_{1}^{\max }$ are pinned down by the second, third, and fourth FOCs. At the $\lambda_{1}^{*}=1-\bar{t}$ corner solution, $\lambda_{0}^{*}, h_{0}^{\max }$, and $h_{1}^{\max }$ are pinned down by the 
first, third and fourth FOCs. If both $\lambda_{1}^{*}$ and $\lambda_{0}^{*}$ are at corner solutions, only the third and fourth FOCs apply. In each case, we solve the general four equation system and then proceed to the corner solution cases if $\lambda_{0}^{*}$ or $\lambda_{1}^{*}$ are not in the correct intervals. There may also be a corner solution for hours if $h_{0}\left(\lambda_{0}\right)>1$ for some $\lambda_{0}$; this case is considered separately in a subsequent section.

Having solved for $\lambda_{0}^{*}, \lambda_{1}^{*}, h_{0}^{\max }$, and $h_{1}^{\max }$, we can then calculate retirement dates and build the hours profile. Let $A_{i}^{E}$ be the labor market entry date and $A_{i}^{R}$ be the labor market exit date under tax system $i$. If $\lambda_{1}^{*}<1-2 \bar{t}$, the working life will be entirely after $\bar{t}$. The individual will enter the labor force at date $A_{1}^{E}=.5-\frac{\lambda^{*}}{2}$ and exit at date $A_{1}^{R}=.5+\frac{\lambda^{*}}{2}$. If $\lambda_{1}^{*}>1-2 \bar{t}$, the agent will have already started working so $A_{1}^{E}=\bar{t}$. They will thus exit at date $A_{1}^{R}=\bar{t}+\lambda^{*}$. As for $\lambda_{0}^{*}$, if $\lambda_{0}^{*}=0$ the worker does not work between $\underline{t}$ and $\bar{t}$. If $\bar{t}<.5$, then $A_{0}^{E}=\bar{t}-\lambda_{0}^{*}$ and $A_{0}^{R}=\bar{t}$. If $\underline{t}>.5$, then $A_{0}^{E}=\underline{t}$ and $A_{0}^{R}=\underline{t}+\lambda_{0}^{*}$. If $\underline{t}<.5$ and $\bar{t}>.5$, there are three cases. If $.5-\underline{t}<\bar{t}-.5$, there are two cases: if $2 \lambda_{0}<.5-\underline{t}$ then $A_{0}^{E}=.5-\frac{\lambda_{0}^{*}}{2}$ and $A_{0}^{R}=.5+\frac{\lambda_{0}^{*}}{2}$ and otherwise $A_{0}^{E}=\underline{t}$ and $A_{0}^{R}=\underline{t}+\lambda_{0}$. If $.5-\underline{t} \geq \bar{t}-.5$, there are two cases: if $2 \lambda_{0}<\bar{t}-.5$ then $A_{0}^{E}=.-\frac{\lambda_{0}^{*}}{2}$ and $A_{0}^{R}=.5+\frac{\lambda_{0}^{*}}{2}$ otherwise $A_{0}^{E}=\bar{t}-\lambda_{0}$ and $A_{0}^{R}=\bar{t}$.

In order to build the hours profile, we proceed as in the EITC section and build a $\lambda(a)$ function. $\lambda_{1}(a)$ looks the same as $\lambda(a)$ in the EITC simulation with $\underline{t}$ replacing $\bar{t}$. For $\lambda_{0}(a)$, if $\bar{t}<.5$,

$$
\lambda_{0}(a)=\bar{t}-a
$$

if $\underline{t}>.5$,

$$
\lambda_{0}(a)=a-\underline{t}
$$

If $\underline{t}<.5$ and $\bar{t}>.5$, there are two cases: if $.5-\underline{t}<\bar{t}-.5$,

$$
\lambda_{0}(a)=\left\{\begin{array}{c}
2|a-.5| \text { if } a<1-\underline{t} \\
a-\underline{t} \text { otherwise }
\end{array}\right.
$$

and if $.5-\underline{t}>\bar{t}-.5$

$$
\lambda_{0}(a)=\left\{\begin{array}{c}
2|a-.5| \text { if } a>1-\bar{t} \\
\bar{t}-a \text { otherwise }
\end{array}\right.
$$

The hours profile can then be generated from the $\lambda_{0}(a)$ and $\lambda_{1}(a)$ functions as with a permanent tax change.

Calculating Elasticities. The elasticities reported in the text and appendix A are constructed by simulation. For all of the simulations, we compare labor supply under the prequasi-experimental tax regime $\tau$ to labor supply under a tax regime of $\tau-.01$ to approximate an infinitesimal tax change. Denoting hours under the two tax regimes by $h_{1}$ and $h_{2}$, respectively, the elasticity is calculated as:

$$
\varepsilon=\frac{\ln \left(\frac{h_{2}}{h_{1}}\right)}{\ln \left(\frac{1-\tau+.01}{1-\tau}\right)}
$$

To calculate the Frisch elasticities, we treat the tax change from $\tau$ to $\tau-.01$ as a temporary tax change lasting $\frac{1}{6,000}$ units of time using 6,000 generations to approximate a tax change for an infinitesimal moment. Our reported elasticities are thus an approximation to an experiment 
in which net-of-tax wages are raised by $d w$ for a time period $d t$. We report three intertemporal substitution elasticities: the intensive margin Frisch elasticity, which we know will be $\frac{1}{\gamma}$ from the derivation above, a participation Frisch elasticity, and an aggregate hours Frisch elasticity. For the aggregate hours elasticity, $h_{1}$ and $h_{2}$ are aggregate hours. For the participation elasticity, $h_{1}$ and $h_{2}$ are labor force participation rates. For the intensive margin elasticity $h_{1}$ and $h_{2}$ are aggregate hours for generations that would have supplied labor in the period of the tax change if the tax change had not occurred.

To calculate compensated elasticities, we compare the model's steady state under a tax regime of $\tau$ and a tax regime of $\tau-.01$. Our reported elasticities are thus an approximation to an experiment in which net-of-tax wages are raised permanently by $d w$ and agents' unearned income is reduced by a commensurate amount. We report three elasticities: the intensive margin compensated elasticity, the participation compensated elasticity, and the aggregate hours compensated elasticity, which are computed in the same manner as described in the previous paragraph.

Aggregation Over Generations. The analytical methods above are used to solve for the labor supply of a given generation. We aggregate over generations to calculate the impacts of a tax change on aggregate labor supply. To approximate a continuous time environment in which a new generation is born every instant, we use numerical simulations with a large number of generations. In particular, we project the analytical solution onto a discrete-time grid for each generation, with one generation born every time period. For the Iceland simulation, we use 9,360 generations, so three generations are born or die each week. For the Canada SSP simulation, we use 7,200 generations, so 10 generations are born or die each month. For the EITC simulation, we use 6,000 generations, so 100 generations are born or die each year. We then bin the data to report the fraction of the population that worked at any point in the last week (for Iceland), month (for Canada), or year (for EITC), so that we are consistent with the quasi-experimental data. For the EITC simulation, we then aggregate up to years to reflect Bianchi et al.'s data. 
TABLE 1

Extensive Margin Elasticity Estimates from Quasi-Experimental Studies

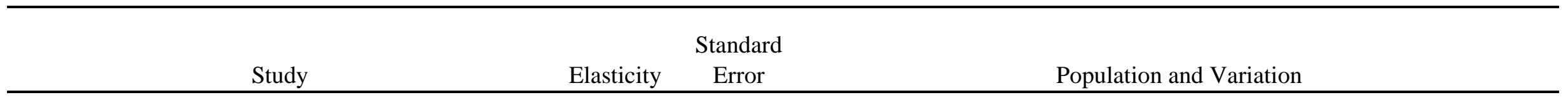

\section{A. Steady State (Hicksian) Elasticities}

1. Juhn, Murphy, and Topel (1991)

2. Eissa and Liebman (1996)

3. Graversen (1998)

4. Meyer and Rosenbaum (2001)

5. Devereux (2004)

6. Eissa and Hoynes (2004)

7. Liebman and Saez (2006)

8. Meghir and Phillips (2010)

9. Blundell, Bozio, and Laroque (2011)

Unweighted Mean

\section{B. Intertemporal Substitution (Frisch) Elasticities}

\author{
10. Carrington (1996) \\ 11. Gruber and Wise (1999) \\ 12. Bianchi, Gudmunndsson, and Zoega (2001) \\ 13. Card and Hyslop (2005) \\ 14. Brown (2009) \\ 15. Manoli and Weber (2011)
}

\section{Unweighted Mean}

0.02 Men, skill-specific trends, 1971-1990

0.10 Single Mothers, U.S. 1984-1990

0.04 Women, Denmark 1986 tax reform

0.05 Single Women, U.S. Welfare Reforms 1985-1997

0.17 Married Women, U.S. wage trends 1980-1990

0.07 Low-Income Married Men \& Women, U.S. EITC expansions 1984-1996

0.30 Women Married to High Income Men, U.S. tax reforms 1991-97

0.08 Low-Education Men, U.K. wage trends, 1994-2004

n/a Prime-age Men and Women, U.K., tax reforms 1978-2007

\footnotetext{
Notes: This table reports elasticities of employment rates with respect to wages, defined as the log change in employment rates divided by the log change in net-of-tax wages. Where possible, we report elasticities from the authors' preferred specification. When estimates are available for multiple populations or for multiple specifications without a stated preference among them, we report an unweighted mean of the relevant elasticities. See Appendix B for details on sources of estimates.
} 
TABLE 2

Micro vs. Macro Labor Supply Elasticities

\begin{tabular}{lccc|c}
\hline \hline & & Intensive Margin & Extensive Margin & Aggregate Hours \\
\hline \multirow{2}{*}{ Steady State (Hicksian) } & micro & 0.33 & 0.25 & 0.58 \\
& macro & 0.33 & 0.17 & 0.50 \\
\hline Intertemporal Substitution & micro & 0.54 & 0.32 & 0.86 \\
(Frisch) & macro & {$[0.54]$} & {$[2.77]$} & 3.31 \\
\hline \hline
\end{tabular}

Notes: Each cell shows a point estimate of the relevant elasticity based on meta analyses of existing micro and macro evidence. Micro estimates are identified from quasi-experimental studies; macro estimates are identified from cross-country variation in tax rates (steady state elasticities) and business cycle fluctuations (intertemporal substitution elasticities). The aggregate hours elasticity is defined as the sum of the extensive and intensive elasticities. Macro studies report intertemporal aggregate hours elasticities but do not always decompose these values into extensive and intensive elasticities. Therefore, the estimates in brackets show the values implied by the macro aggregate hours elasticity if the intensive Frisch elasticity is chosen to match the micro estimate of 0.54 . See Appendix $\mathrm{C}$ for sources of these estimates. 


\section{FIGURE 1}

\section{Impacts of Tax Changes on Employment Rates: Simulations vs. Data}

(a) 1987 Tax Holiday in Iceland

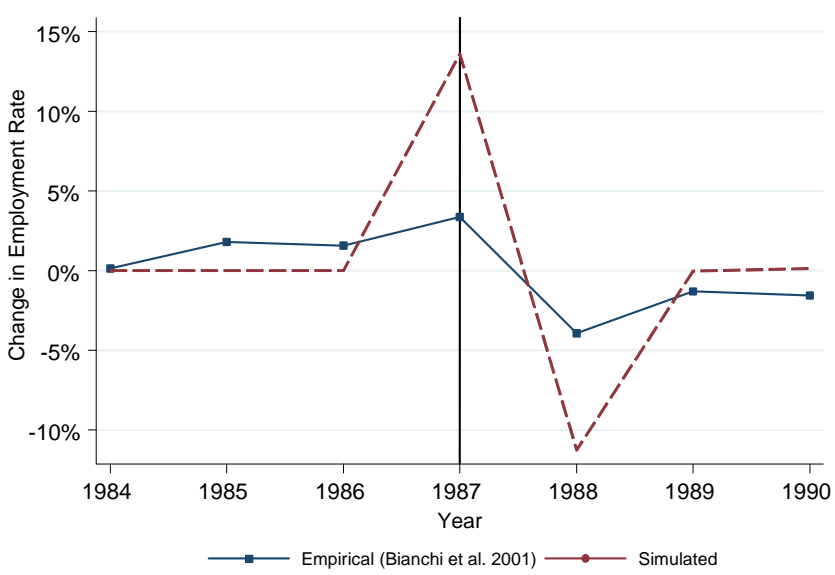

(b) SSP Welfare Experiment in Canada

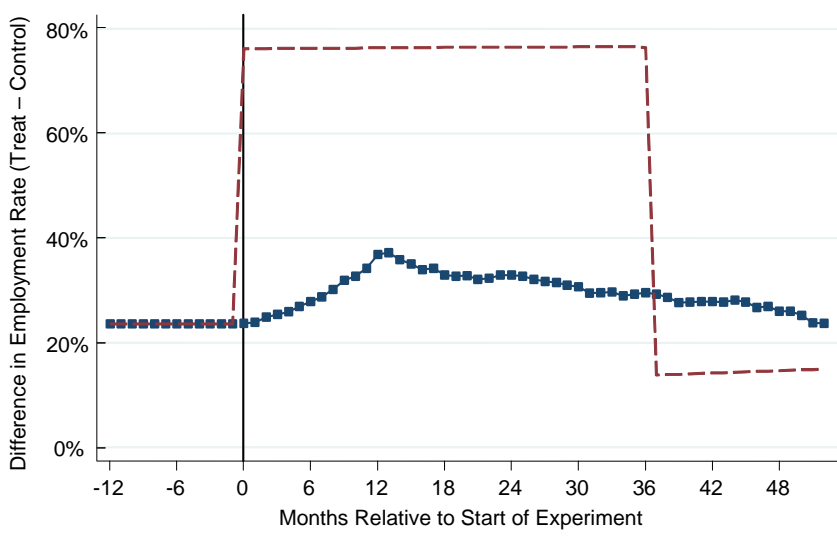

(c) 1994 EITC Expansion in the United States

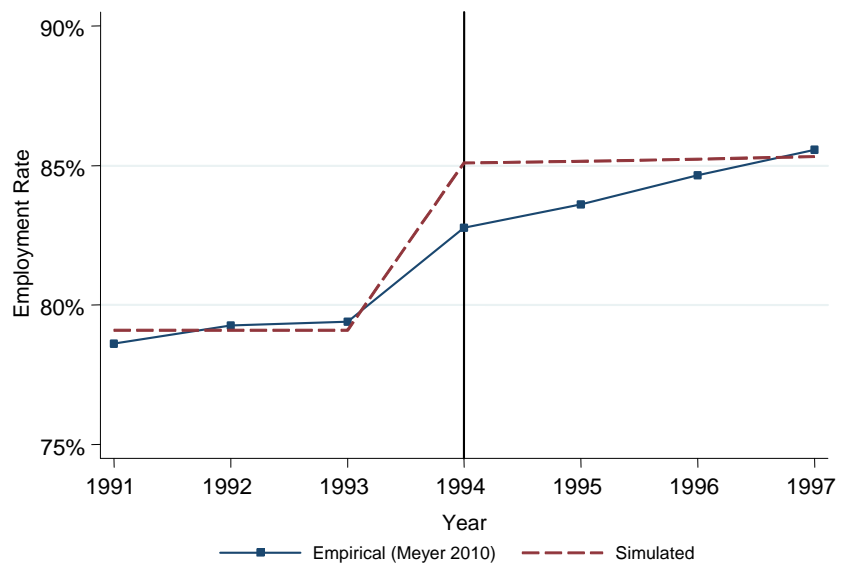

Notes: Each panel shows the impact of an unanticipated change in incentives to work on employment rates. The red dashed series shows the impact predicted by the calibrated Rogerson and Wallenius (2009) model, while the blue solid series shows the impact observed in the data. Panel (a): Iceland suspended its income tax for one year in 1987. Average tax rates in Iceland changed from $14.5 \%$ in 1986 to $0 \%$ in 1987 and then $8.0 \%$ in 1988. Following Bianchi et al. (2001), we define the employment rate as the fraction of weeks worked in a given year in the adult population. This panel plots annual changes in employment rates. Panel (b): The Canadian SSP demonstration randomly assigned a group of welfare recipients a wage subsidy for 36 months in the early 1990s. Individuals in the control group faced an effective average tax rate of $74.3 \%$ for working full time at the minimum wage, while individuals in the treatment group faced an effective average tax rate of $16.7 \%$. Following Card and Hyslop (2005), we plot the difference in monthly employment rates between the treatment and control groups. We add the observed control group mean at the start of the experiment (23.5\%) to the difference for scaling purposes. Simulated employment rates are the fraction of individuals aged 16 to 46 working in a given month, reflecting the age distribution of the SSP treatment group (see Appendix A). Panel (c): The EITC expansion in the US in 1994-5 lowered average tax rates net of taxes and transfers for single mothers from 50.8\% in 1992 to 43.6\% in 1996. Meyer (2010, Figure 2) reports annual employment rates for single women using CPS data. We plot the employment rates of single mothers adjusted for observables and time trends as in Meyer (2010); simulated employment rates are reported for individuals aged 16 to 46. 


\section{FIGURE 2 \\ Micro Predictions Versus Macro Data}

a) Aggregate Hours vs. Net-of-Tax Rates Across Countries (Prescott Data)

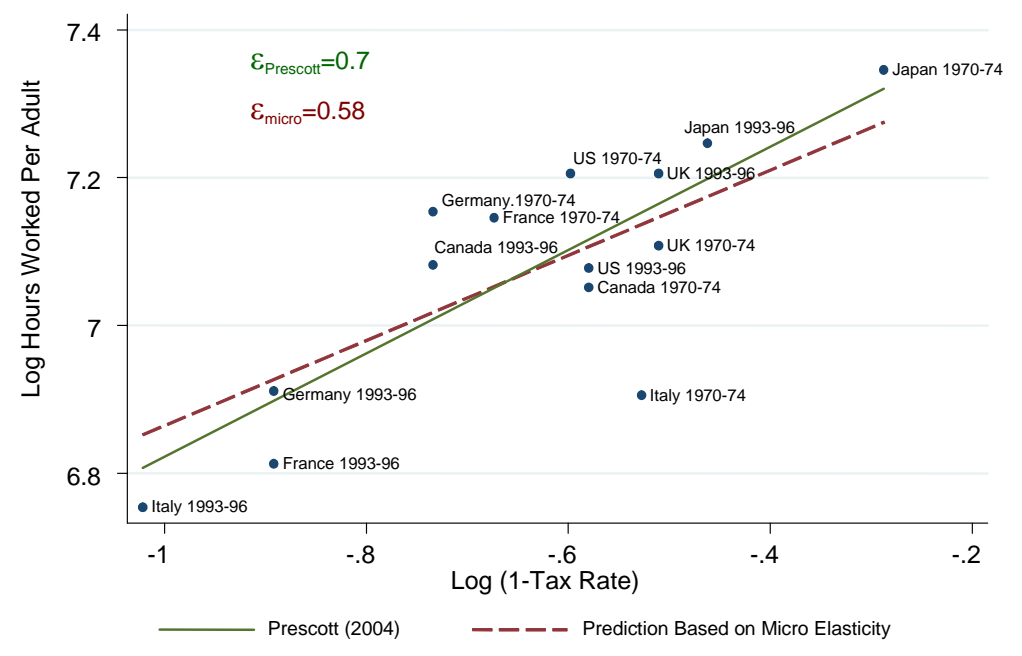

b) Business Cycle Fluctuations in Employment Rates in the U.S.

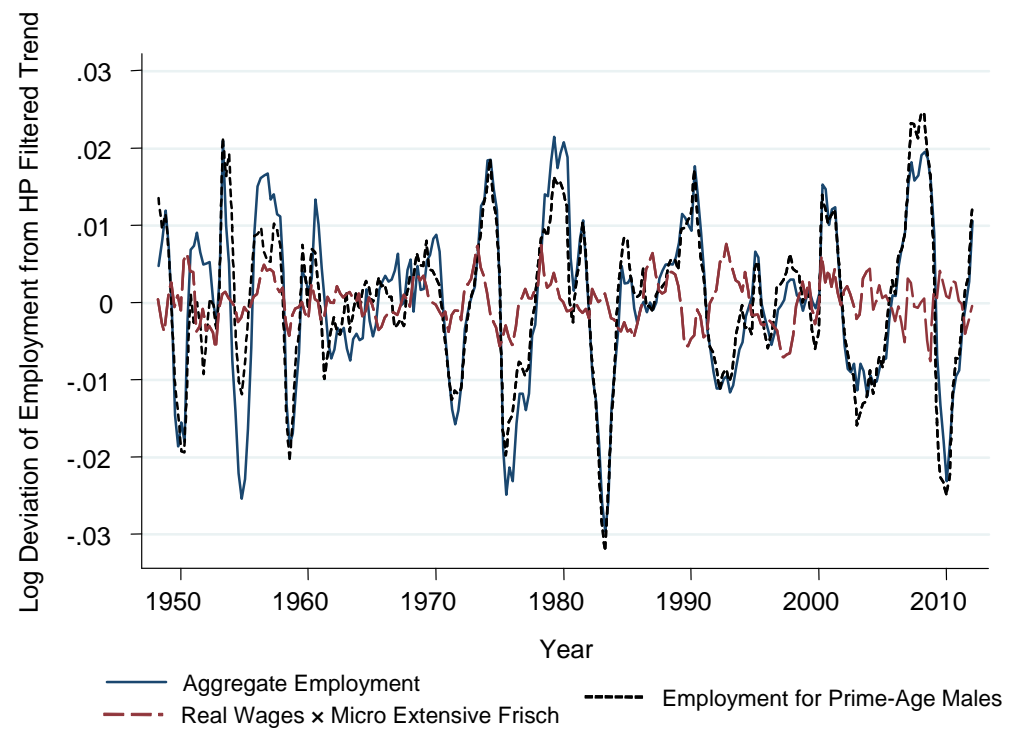

Notes: Panel A plots log hours worked per adult vs. log of 1 - average tax rate using data from Prescott (2004) across countries and time periods described in Appendix C. The data imply an aggregate hours Hicksian elasticity of .7, as shown by the solid green best fit line. The dashed red line is drawn through the mean of the $\mathrm{x}$ and $\mathrm{y}$ values with a slope of 0.58 , in accordance with the aggregate hours micro elasticity from Table 2. Panel B plots the log deviation of employment from a Hodrick-Prescott filtered trend for the United States from 1948 to 2008. The data is taken from the Bureau of Labor Statistics and available at http://www.bls.gov. The solid blue line is generated using seasonally adjusted quarterly data on employment tabulated from the Current Population Survey, series LNS12000000Q. The raw data was Hodrick-Prescott filtered using a smoothing parameter of 1600 . The dotted black line is taken from the same source for men ages 25-54, series LNS12000061Q. The dashed red line is a projected employment series based on fluctuations in real wages. Real wages are measured as real hourly compensation for the nonfarm business sector, Bureau of Labor Statistics series PRS85006153. To generate the projection, real wages are Hodrick-Prescott filtered using a smoothing parameter of 1600 and multiplied by the micro extensive margin Frisch elasticity of 0.32 from Table 1. 